\title{
IG NORK \\ Understanding the Mechanisms Linking College Education with Longevity
}

\author{
Kai Hong \\ Peter A. Savelyev \\ Kegon T. K. Tan
}

Working Paper

2020-022

$04 / 2020$

HUMAN CAPITAL AND

ECONOMIC OPPORTUNITY

GLOBAL WORKING GROUP
The University of Chicago 1126 E. 59th Street Box 107 Chicago IL 60637 


\title{
Understanding the Mechanisms Linking College Education with Longevity*
}

\author{
Kai Hong ${ }^{\dagger}$ Peter A. Savelyev ${ }^{\ddagger}$ Kegon T. K. Tan $^{\S}$ \\ New York University College of William \& Mary University of Rochester \\ March 31, 2020
}

\begin{abstract}
*This paper is accepted for publication by the Journal of Human Capital conditional on minor edits, which are made in this version of the working paper. A version of this paper was presented to the $9^{\text {th }}$ Annual Health Econometrics Workshop at Washington University in St. Louis; to the Human Capital and Health Behavior Symposium at the Centre for Health Economics, University of Gothenburg; to the $24^{\text {th }}$ European Workshop on Econometrics and Health Economics in Paris; to the CIREQ Montreal Applied Economics Conference on the Socioeconomic Determinants of Health; to economics research seminars at Johns Hopkins, The University of Montreal, Tinbergen Labor Seminar in Amsterdam; Econometrics and Statistics Seminar at Tilburg University; Tinbergen Health Economics Seminar at the University of Rotterdam; Applied Microeconomics Workshop at the Institute of Applied Microeconomics of the University of Bonn; Alexander von Humboldt Seminar at the University of Mannheim; Applied Econometrics Workshop at the University of Alicante; Economic Theory Seminar at the University of Barcelona; Concordia University, Indiana University, The College of William \& Mary; Microeconomics Seminar at Vanderbilt University; UW Madison Applied Microeconomics Lunch; and Vanderbilt Empirical Applied Micro Work-In-Progress Lunch. We thank participants of these meetings for their helpful suggestions and stimulating discussions. We are grateful to Govert Bijwaard, Evan Elmore, Dave Frisvold, Titus Galama, Michael Gerfin, Federico Gutierrez, Nick Papageorge, Pedro Sant'Anna, Laura Turner, Ben Ward, and to anonymous referees for their detailed and productive comments. Hong and Savelyev gratefully acknowledge support from the NSF 1460003 grant and the Faculty-Graduate Student Collaboration grant at Vanderbilt. Savelyev also benefited from the financial support of the Grey Research Fund at Vanderbilt University and the Faculty Research Fund at The College of William \& Mary. Hong also benefited from support from Vanderbilt and New York Universities. Tan gratefully acknowledges support from The University of Wisconsin-Madison, Human Capital and Economic Opportunity Global Working Group sponsored by The Institute for New Economic Thinking, and The University of Rochester. Funders had no involvement in study design; in the collection, analysis, and interpretation of the data; in the writing of the manuscript; and in the decision to submit the article for publication. We thank Max Sacher for his excellent research assistance. William Anderson, Atticus Bolyard, Xiaoyu (Nancy) Chen, and Isabel Haber provided great help with proofreading the manuscript. Supplementary materials may be retrieved from https://wmpeople.wm.edu/asset/index/pasavelyev/wlsmediationwebappx.

${ }^{\dagger}$ Robert F. Wagner Graduate School of Public Service, New York University.

†The corresponding author. Department of Economics, The College of William \& Mary and IZA.

$\S$ Department of Economics, The University of Rochester.
\end{abstract}




\begin{abstract}
We go beyond estimating the effect of college attainment on longevity by uncovering the mechanisms behind this effect while controlling for latent skills and unobserved heterogeneity. We decompose the effect with respect to a large set of potential mechanisms, including health behaviors, lifestyles, earnings, work conditions, and health at the start of the risk period (1993-2017). Our estimates are based on the Wisconsin Longitudinal Study and show that the effect of education on longevity is well explained by observed mechanisms. Furthermore, we find that for women, the positive effect of education on longevity has been historically masked by the negative effect of education on marriage. An adjustment for the relationship between education and marriage based on data for more recent cohorts increases the explained effect of education on longevity for women. We discuss the implications for policies aimed at improving health and longevity and reducing health inequality.
\end{abstract}

Key words: college education, longevity, mechanisms, health behaviors, lifestyles

JEL codes: C41, I12, J24 


\section{INTRODUCTION}

This paper is motivated by the conclusions of a recent comprehensive survey of the literature on the effect of education on health and longevity by Galama, LlerasMuney, and van Kippersluis (2018). The authors report strong and puzzling heterogeneity in results across quasi-experimental studies linking education with health and longevity, and recommend that future studies move beyond asking whether or not "there is an effect" to tracing the pathways through which education impacts health. They note that future work should link short-, medium-, and long-term outcomes and study important determinants of mortality, such as health behaviors or income across the life cycle. Our paper perfectly matches these recommendations. We decompose education-longevity gradients by performing a thorough decomposition analysis using a comprehensive set of behavioral mechanisms.

Our decomposition analysis supports the causal link between education and longevity by improving our understanding of the mechanisms driving the educationlongevity gradient. ${ }^{1}$ To draw a parallel, the Surgeon General Report on smoking (Bayne-Jones et al., 1964) was influential about the then-controversial effect of smoking on health, despite the lack of direct experimental evidence, because it was convincing about the mechanisms behind the effect.

Deepening our understanding of the drivers behind the education-longevity gradient helps explain the well-documented sex difference in the estimated effect

\footnotetext{
${ }^{1}$ By "support" we mean an increased prior about the likelihood of the causal effect.
} 
of education on longevity, which tends to be larger for men than for women. We show that mechanisms related to the marriage market and to taking dangerous jobs have historically contributed to this difference.

Finally, we offer a framework that allows us to make counterfactual predictions for later cohorts and different economic environments. We demonstrate its use for questions relevant for external validity and health policy.

We use the Wisconsin Longitudinal Survey (WLS), which is based on a sample of approximately 10,000 high school graduates from the state of Wisconsin, USA. Subjects were first surveyed in 1957, when they graduated from high school, and have been followed ever since. The WLS is well suited for studying determinants of longevity given its long panel and rich information on health behaviors, health status, and mortality. Furthermore, the WLS contains measures of IQ, school achievement, and education. Finally, it captures detailed family background variables.

We rely on a full information maximum likelihood estimation of a system of equations. These equations model the relationships between education, lifestyles, income, work conditions, health, and mortality. The system is recursive, as we take advantage of natural exclusion restrictions: early outcomes affect later outcomes but not the reverse. We use factor analysis to control for measurement error in measures of skills and health. We control for latent skills to capture usual confounders, such as perseverance and the ability to delay gratification as in Heckman et al. (2006). Conditional on the latent skill factor, we model the error term as 
unobserved heterogeneity plus idiosyncratic error. Controlling for unobserved heterogeneity has a major influence on our results. Our model is supported by placebo tests, proportional hazard tests, as well as other specification tests and robustness checks. $^{2}$

We account for unobserved heterogeneity across equations through a semiparametric heterogeneity model (Heckman and Singer, 1984; Mroz, 1999). ${ }^{3}$ Our modeling of unobserved heterogeneity allows us to flexibly account for common confounding influences that may still exist despite conditioning on IQ, latent skills, and a rich set of controls. In particular, our unobserved heterogeneity term should account for early health including health in utero (e.g., Conti et al., 2019), early cognitive and noncognitive skills (e.g., Almlund et al., 2011; Heckman et al., 2006), parental preferences for investments in both health capital and skill capital (e.g., Belfield and Kelly, 2012; Ehrlich and Yin, 2013), as well as other possible unobserved confounders.

Empirical results include the estimation of the total effect of college education on longevity, its decomposition, and policy simulations. We estimate the total effect using two different measures of longevity. First, we calculate a reduction in the hazard of death induced by a completed four-year college degree. We estimate that for men, a college education reduces the hazard of death by $32 \%(p=0.001)$. Unlike for

\footnotetext{
${ }^{2}$ See Figure A-1 and Tables A-1-A-5 of Web Appendix A, Web Appendix B, and Table C-2 of Web Appendix $C$. We return to each of these tests later in the paper.

${ }^{3}$ The model is also referred to in the literature as a "latent class model" (Aitken and Rubin, 1985), a "discrete factor approximation model" (Mroz, 1999), a "finite mixture model" (Cameron and Trivedi, 2005), and a "discrete factor random-effects model" (Gilleskie, 2014).
} 
men, the reduction of the hazard of death for women is not precisely determined $(8 \%, p=0.264)$. However, the estimate for women increases up to $13 \%$ and becomes borderline statistically significant $(p=0.146)$ once we adjust for the relationship between college education and marriage for more recent cohorts. Moreover, when we use late-life health instead of longevity as an outcome, we find strong and statistically significant effects of college education for both men and women. ${ }^{4}$

Second, we calculate an increase in life expectancy at age 53 . We find the effect to be 3.3 and 0.5 additional years of expected life for men and women respectively worth 277 and 50 thousand US dollars (USD), based on the methodology of life expectancy evaluation proposed by Murphy and Topel (2006). ${ }^{5}$ An adjustment for more recent cohorts changes the effect on women's life expectancy up to 0.9 years worth up to 90 thousand USD.

We decompose the total effects with respect to mid-life mechanisms and explain approximately $60 \%$ of the total effect for men. The key contributing mechanisms for men are the health stock at the start of the risk period, ${ }^{6}$ smoking, being overweight, and having a dangerous job. For women, the key mechanisms are health stock, income, and physical exercise, but not dangerous jobs. However, the contribution of these mechanisms for women is diminished by a lower likelihood of marriage. This result is specific to women from our sample born in the late 1930s and is not

\footnotetext{
${ }^{4}$ We use health measures in year 2011, which corresponds to approximately 72 years of age. The effect is an increase of latent health in 2011 by 0.19 standard deviations (s.d.) for men $(p=0.010)$ and by 0.12 s.d. for women ( $p=0.021)$ (without adjustment for the marriage effect).

${ }^{5}$ Values are in 2012 price level.

${ }^{6}$ The risk period in this paper is a period from 1993 to 2017, over which we model the hazard of death.
} 
applicable to women today, as college educated women are no longer less likely to be married in midlife (Lefgren and McIntyre, 2006).

Lastly, we demonstrate model simulations for the following environmental changes: (1) a hypothetical increase in the taxation rates of cigarettes and (2) a reversal of the effect of education on marriage for women. We conclude that health disparities induced by education are hard to close by targeting one specific mechanism in midlife, even if the mechanism is strong, and that changes in marriage markets in the course of the 20th Century likely led to stronger effects of education on longevity for women.

\section{DATA}

We use the Wisconsin Longitudinal Study (WLS) (Hauser and Sewell, 2005), which follows approximately 10,000 individuals from Wisconsin who were first surveyed at high school graduation in 1957. ${ }^{7}$ Subjects were born between 1937 and 1940. The study represents white, non-Hispanic high school graduates. ${ }^{8}$ Herd et al. (2014) argue that the WLS is broadly representative of white American men and women with at least a high school education.

\footnotetext{
${ }^{7}$ An important alternative dataset often used for health studies is the Health and Retirement Study (HRS). It has the advantage of being nationally representative and racially diverse, unlike the WLS, but unfortunately it does not capture much information of early life. In this regard, the WLS is uniquely suited for the study of the developmental origins of health and longevity because it is a long panel with a relatively early start and a unique combination of measurements.

${ }^{8}$ There are only 30 minority respondents in the sample, whom we exclude from our statistical analysis because this subsample is too small to reliably study the minority population, for whom effects and mechanisms may differ. In 1940, which is the birth year of the youngest individuals in the WLS cohort, the share of whites in Wisconsin was $99.2 \%$.
} 
Table 1: Skill Measures and Background Variables

\begin{tabular}{|c|c|c|c|c|c|}
\hline \multirow[b]{2}{*}{ Variable } & \multirow[b]{2}{*}{$\begin{array}{r}\text { Year } \\
\text { measured }\end{array}$} & \multicolumn{2}{|c|}{ Males } & \multicolumn{2}{|c|}{ Females } \\
\hline & & Mean & $\begin{array}{l}\text { Std. } \\
\text { dev. }\end{array}$ & Mean & $\begin{array}{l}\text { Std. } \\
\text { dev. }\end{array}$ \\
\hline $\mathrm{IQ}^{(\mathrm{a})}$ & 1957 & 101.5 & 15.2 & 101.0 & 14.4 \\
\hline \multicolumn{6}{|l|}{ Academic achievement at high school } \\
\hline High school ranking ${ }^{(b)}$ & 1957 & 97.9 & 14.5 & 104.5 & 14.3 \\
\hline Member of an honor society & 1957 & 0.044 & 0.204 & 0.063 & 0.243 \\
\hline Outstanding student $\mathrm{c}^{(\mathrm{c})}$ & 1957 & 0.100 & 0.301 & 0.118 & 0.323 \\
\hline \multicolumn{6}{|l|}{ Early behaviors } \\
\hline Smoking tobacco ${ }^{(\mathrm{d})}$ & 1992 & 0.225 & 0.418 & 0.183 & 0.386 \\
\hline Marriage $^{(\mathrm{e})}$ & 1992 & 0.547 & 0.498 & 0.679 & 0.467 \\
\hline \multicolumn{6}{|l|}{ Other background variables } \\
\hline Father farmer or farm manager & 1957 & 0.200 & 0.400 & 0.198 & 0.398 \\
\hline Father white collar employee & 1957 & 0.301 & 0.459 & 0.299 & 0.458 \\
\hline Father has attended college $\mathrm{f}^{(\mathrm{f})}$ & 1957 & 0.160 & 0.367 & 0.145 & 0.352 \\
\hline Mother has attended college $\mathrm{f}^{(\mathrm{f})}$ & 1957 & 0.144 & 0.351 & 0.150 & 0.357 \\
\hline Parental income $(\log )^{(g)}$ & 1957 & 8.536 & 0.695 & 8.532 & 0.666 \\
\hline High school in a rural area & 1957 & 0.187 & 0.390 & 0.187 & 0.390 \\
\hline Resided in a metropolitan area ${ }^{(\mathrm{h})}$ & 1957 & 0.337 & 0.473 & 0.366 & 0.482 \\
\hline Respondent's number of siblings & 1975 & 3.170 & 2.522 & 3.284 & 2.561 \\
\hline First-born or the only child & 1975 & 0.407 & 0.491 & 0.375 & 0.484 \\
\hline Second-born & 1975 & 0.261 & 0.439 & 0.274 & 0.446 \\
\hline Third-born & 1975 & 0.144 & 0.351 & 0.142 & 0.349 \\
\hline Fourth-born or above & 1975 & 0.188 & 0.391 & 0.208 & 0.406 \\
\hline Respondent is overweight ${ }^{(i)}$ & 1957 & 0.195 & 0.396 & 0.206 & 0.404 \\
\hline Respondent is underweight ${ }^{(j)}$ & 1957 & 0.089 & 0.285 & 0.107 & 0.309 \\
\hline Grew up with smoker ${ }^{(1)}$ & 1957 & 0.757 & 0.429 & 0.734 & 0.442 \\
\hline Grew up with drinker & 1992 & 0.184 & 0.387 & 0.220 & 0.415 \\
\hline Birth year 1937-38 & 1957 & 0.216 & 0.411 & 0.144 & 0.351 \\
\hline Birth year 1939 & 1957 & 0.746 & 0.435 & 0.804 & 0.397 \\
\hline Birth year 1940 & 1957 & 0.038 & 0.192 & 0.053 & 0.223 \\
\hline Sample size & & \multicolumn{2}{|c|}{3961} & \multicolumn{2}{|c|}{4491} \\
\hline
\end{tabular}

Notes: Calculations are based on the WLS data. "Std. dev." stands for "standard deviation." ${ }^{(a) H e n m o n-N e l s o n}$ test score. ${ }^{(b)}$ Standardized high school grades percentile rank. (c) Teacher's evaluation of the high school graduate as "outstanding." (d) The respondent first started smoking before the median age of college graduation for whites in the 1950s-1960s: 23.4 for men and 22.2 for women. ${ }^{(\mathrm{e})}$ The first marriage occurred before the median age of college graduation. ${ }^{(\mathrm{f})}$ At least some college coursework or above. ${ }^{(\mathrm{g})}$ Calculated as $\log \left(1+\right.$ parental income). ${ }^{(\mathrm{h})}$ Includes Madison and Milwaukee, as well as Brown, Kenosha, Racine, and Douglas counties. ${ }^{(i)}$ BMI in 1957 is above 80th percentile. ${ }^{(j)} \mathrm{BMI}$ in 1957 is below 10th percentile. ${ }^{(1)}$ Up until 16 years old. 
Table 1 documents descriptive statistics for skills, background variables, and early behaviors. We observe measures of IQ and high school achievement at high school graduation in 1957. We also observe background variables, including number of siblings, order of birth, degree of urbanization, and parental education, occupation, and income. In addition, we learn about early behaviors from a later survey: tobacco use and early marriage. Early smoking could confound the effect of schooling on smoking in adulthood (Farrell and Fuchs, 1982). Early marriage may increase the probability of dropping out of college, especially for women of this generation (Goldin, 1997). ${ }^{9}$

Table 2 documents descriptive statistics of education, potential mechanisms, physical health measures, and mortality. Approximately $31 \%$ of men and $18 \%$ of women earn at least a Bachelor's degree. Potential mechanisms include health behaviors, lifestyles, and job market outcomes. Measures of physical health include self-rated general health and reports of major illness, staying in bed, and staying in a hospital over the last year.

The most recent death status data are available for 2017, at which time surviving respondents reach up to 80 years of age. Approximately $30 \%$ of men and $22 \%$ of women died between 1993 and 2017. The WLS maximizes the accuracy of its mortality measures by relying on multiple sources: relatives of the respondents, the Social Security Administration's Death Index, and the National Death Index.

\footnotetext{
${ }^{9}$ We do not have access to other pre-college health behaviors and lifestyles, but those two variables are especially important, given the important role that smoking and marriage play in mediating longevity. Plus, we account for unobserved heterogeneity, which approximates unobserved pre-college traits that are relevant for education and health.
} 
Table 2: Education and Health-Related Outcomes

\begin{tabular}{|c|c|c|c|c|c|}
\hline \multirow[b]{2}{*}{ Variable } & \multirow[b]{2}{*}{$\begin{array}{r}\text { Year } \\
\text { measured }\end{array}$} & \multicolumn{2}{|c|}{ Males } & \multicolumn{2}{|c|}{ Females } \\
\hline & & Mean & $\begin{array}{l}\text { Std. } \\
\text { dev. }\end{array}$ & Mean & $\begin{array}{l}\text { Std. } \\
\text { dev. }\end{array}$ \\
\hline \multicolumn{6}{|l|}{ Education } \\
\hline Bachelor's degree or above & 1975-1992 & 0.306 & 0.461 & 0.178 & 0.382 \\
\hline \multicolumn{6}{|l|}{ Potential mediators } \\
\hline Smoking tobacco ${ }^{(a)}$ & 1992 & 0.175 & 0.380 & 0.178 & 0.383 \\
\hline Risky drinking of alcohol ${ }^{(b)}$ & 1992 & 0.082 & 0.274 & 0.061 & 0.239 \\
\hline Physical exercise ${ }^{(\mathrm{c})}$ & 1992 & 0.830 & 0.376 & 0.788 & 0.409 \\
\hline Overweight $^{(\mathrm{d})}$ & 1992 & 0.201 & 0.401 & 0.166 & 0.372 \\
\hline Marriage $^{(\mathrm{e})}$ & 1992 & 0.851 & 0.356 & 0.798 & 0.402 \\
\hline Social activity ${ }^{(\mathrm{f})}$ & 1992 & 0.887 & 0.316 & 0.798 & 0.401 \\
\hline Household income $(\log )^{(\mathrm{g})}$ & 1992 & 4.116 & 0.736 & 3.837 & 0.883 \\
\hline Dangerous working conditions ${ }^{(\mathrm{h})}$ & 1992 & 0.227 & 0.419 & 0.117 & 0.321 \\
\hline \multicolumn{6}{|l|}{ Measures of physical health } \\
\hline Major illness $^{(i)}$ & 1992 & 0.552 & 0.497 & 0.615 & 0.487 \\
\hline Stayed in bed at least once last year ${ }^{(j)}$ & 1992 & 0.297 & 0.457 & 0.399 & 0.490 \\
\hline Hospitalization at least once last year ${ }^{(\mathrm{k})}$ & 1992 & 0.078 & 0.269 & 0.084 & 0.278 \\
\hline General health $^{(1)}$ & 1992 & 4.137 & 0.666 & 4.163 & 0.679 \\
\hline \multicolumn{6}{|l|}{ Mortality } \\
\hline Died & 1993-2017 & 0.297 & 0.457 & 0.224 & 0.417 \\
\hline Age of death & 1993-2017 & 69.79 & 6.745 & 69.96 & 6.619 \\
\hline Sample size & & \multicolumn{2}{|c|}{3961} & \multicolumn{2}{|c|}{4491} \\
\hline
\end{tabular}

Notes: Calculations are based on the WLS data. "Std. dev." stands for "standard deviation." ${ }^{(a)}$ Currently a tobacco smoker. ${ }^{(b)}$ Either (1) consumed more than 4 alcoholic drinks on average per occasion last month if male or more than 3 if female, or (2) exceeded 14 drinks per average week (in the last month) if male or 7 per week if female (above the threshold for low-risk drinking according the National Institute of Alcohol Abuse and Alcoholism). (c) Respondent does light or heavy exercises at least once per week. (d) Respondent's BMI is above 25. (e) Respondent is currently married. ${ }^{(\mathrm{f})}$ Current participation in at least one social organization, such as a club or a church. ${ }^{(\mathrm{g})}$ Calculated as $\log \left(1+\right.$ household income). ${ }^{(\mathrm{h})}$ Working conditions are classified by the WLS as "extremely dangerous." (i)Major illness includes cancer, diabetes, heart disease, anemia, asthma, arthritis or rheumatism, bronchitis or emphysema, chronic liver trouble, serious back trouble, high blood pressure, circulation problems, kidney or bladder problems, ulcer, allergies, multiple sclerosis, colitis, and other major conditions mentioned by a medical professional. ${ }^{(j)}$ Stayed in bed at least once last year for more than half of the day because of illness or injury. ${ }^{(k)}$ Has been hospitalized at least once last year for at least one night. ${ }^{(1)}$ Self-reported health ranges from 1 (very poor) to 5 (excellent). 
We face data constraints on our modeling of mortality, but these constraints play a negligible role. The WLS introduced a detailed measurement of post-college health-related outcomes in 1992. Therefore, we perform our longevity decomposition study conditional on survival to January 1993. We exclude those attrited as well as those who have missing education information. Only $3.7 \%$ of the initial sample died before 1993. Moreover, we find no evidence of selection into survival on skills, IQ, or post-compulsory education. ${ }^{10}$

\section{METHODOLOGY}

We estimate a simultaneous system of equations, consisting of three parts: a recursive system, a measurement system, and a multinomial logit model. The recursive system links earlier life outcomes to later life outcomes. The measurement system links latent skills and the health stock to their observed measures. The multinomial logit model is needed to relax the common assumption of orthogonality between unobserved heterogeneity and background controls. The model is a test-based simplification of a more general model described in Web Appendix B that allows for more nonlinearities and more controls for potential endogeneity.

The Recursive System Our estimation is conditional on latent early skills $\Theta^{S}$ and detailed controls $\boldsymbol{X}$, which include family background, IQ at high school gradu-

\footnotetext{
${ }^{10}$ See Table A-1 of the Web Appendix.
} 
ation, and health behaviors in early life. ${ }^{11}$ All equations are also conditional on unobserved heterogeneity $\boldsymbol{\mu}$, which accounts for confounders that are missing in $\boldsymbol{X}$ and $\Theta^{S}$. The recursive system links college education $D$ to early skills $\Theta^{S}$, health behaviors $\boldsymbol{B}$ in midlife to college education $D$, health stock $\Theta^{H}$ in midlife to health behaviors $\boldsymbol{B}$, and hazard of death $\lambda(t)$ during the risk period to health behaviors $\boldsymbol{B}$ and health stock $\Theta^{H}$. Figure 1 graphically represents the model conditional on $\boldsymbol{X}$. The recursive system is the following:

$$
\begin{gathered}
D^{*}=a_{1} \boldsymbol{X}+a_{2} \Theta^{S}+a_{3} \Theta^{S} \cdot I Q+\mu_{D}+\epsilon_{D} \\
B_{k}^{*}=b_{1 k} \boldsymbol{X}+b_{2 k} \Theta^{S}+b_{3 k} D+\mu_{B k}+\epsilon_{B k}, k=1, \ldots, K \\
\Theta^{H}=\quad c_{2} \Theta^{S}+c_{3} D+\sum_{k} c_{4 k} B_{k}+\mu_{H}+\epsilon_{H} \\
\ln (\lambda(t))=d_{1} \boldsymbol{X}+d_{2 j} \Theta^{S}+d_{3 j} D+\sum_{k} d_{4 k} B_{k}+d_{5} \Theta^{H} \\
+\mu_{\lambda j}+\ln \left(\lambda_{0}(t)\right), j(t)=1, \ldots, J .
\end{gathered}
$$

A logit model (1) relates pre-college skills $\Theta^{S}$ and other controls to latent index $D^{*}$, which determines the college education outcome $D$, defined as bachelor's degree or above: $D=1$ if $D^{*} \geq 0 ; D=0$ otherwise. Based on specification tests described in Web Appendix B, we allow for an interaction between IQ and skills in Equation (1) but not in other equations. ${ }^{12,13}$

\footnotetext{
${ }^{11}$ In Web Appendix B we show that controlling for potential endogeneity of early life behaviors complicate the model without changing results compared to the main model where these early behaviors are used as background controls.

${ }^{12} \mathrm{IQ}$ is controlled for in all equations that control for $\boldsymbol{X}$, as it is a part of $\boldsymbol{X}$

${ }^{13}$ Our tests in Web Appendix B show that IQ and pre-college skills demonstrate a small positive
} 
Figure 1: Diagram of the Model Conditional on Background Variables $\boldsymbol{X}$

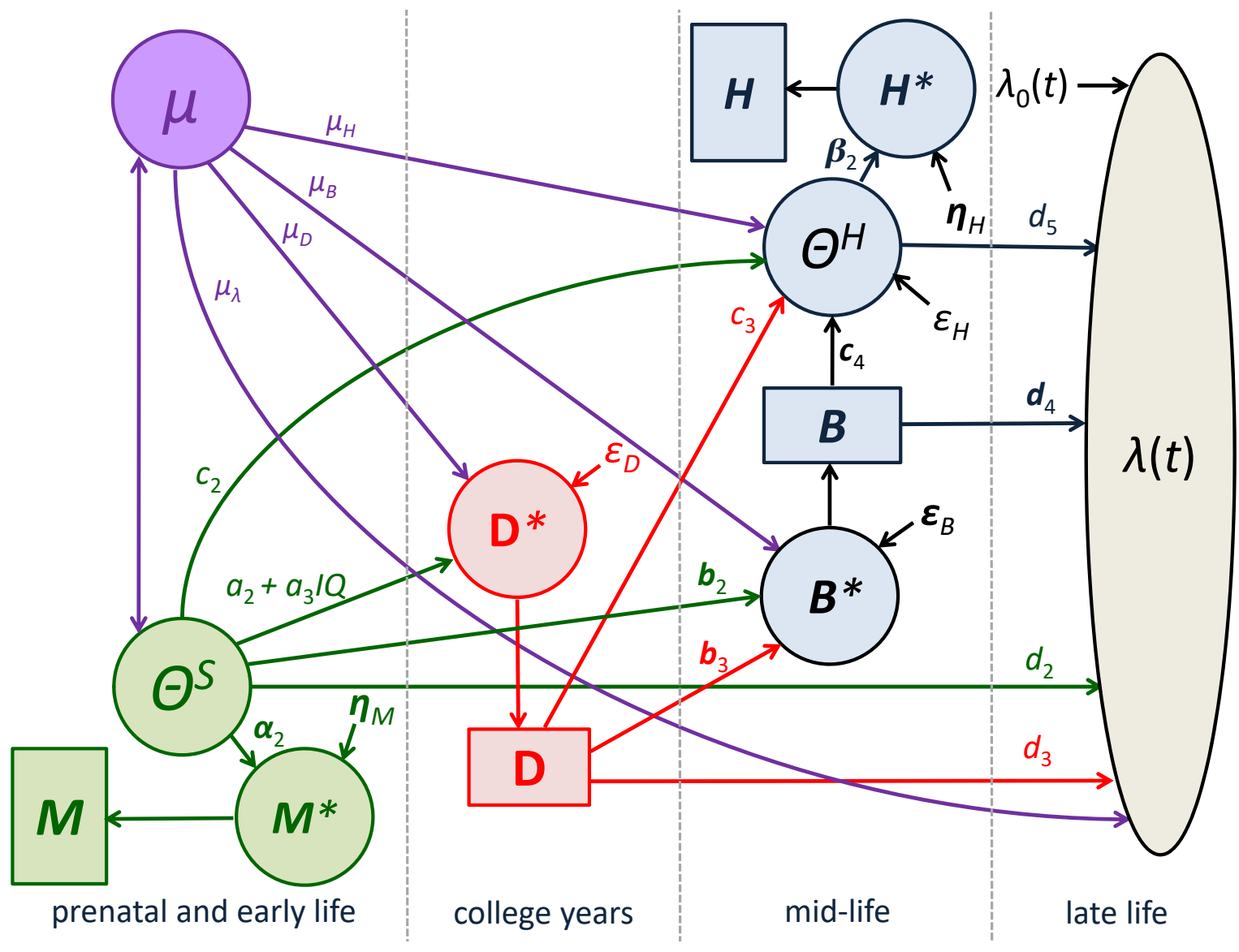

Notes: Rounds and ellipses represent latent variables. Rectangles represent observed variables. Arrows show directions of causal relationships. Double-sided arrows represent correlations. $\Theta^{S}$ denotes latent skills, measured by skill observations $M$; $\mu$ is unobserved heterogeneity, which accounts for unobserved confounders, such as genetic endowments, prenatal environment, and family background that is not captured by $\boldsymbol{X}$ (not shown); $D^{*}$ is a latent propensity for college education measured by binary college education $D ; \Theta^{H}$ is the latent health stock in midlife, measured by health observations $\boldsymbol{H} ; \boldsymbol{B}^{*}$ is a vector of latent propensities for choosing health behaviors, lifestyles, and other health-related outcomes in midlife measured by binary $\boldsymbol{B}$ (with the exception of income, for which $\left.B_{k}^{*}=B_{k}\right) ; \lambda(t)$ represents the hazard of death as a function of time $t ; \lambda_{0}(t)$ represents the baseline hazard of death. Structural coefficients from the model are shown above corresponding arrows. Background variables $\boldsymbol{X}$ are not shown to avoid clutter but their role is similar to the one played by $\Theta^{S}$. 
In turn, education and skills affect index $B_{k}^{*}$ (see Equation (2)), which determines the choice of potential mechanisms of longevity at midlife, $B_{k}$, where $k=1, \ldots, K$ denotes the type of mechanism. For binary mechanisms we use the logit model. For a single continuous mechanism we use a linear model for which $B_{k}^{*}=B_{k}$.

Another mechanism is the latent general health stock at midlife, $\Theta^{H}$, which we relate to its determinants the same as we do for $B_{k}^{*}$ (see Equation (3)). ${ }^{14}$ We also relate the health stock to behaviors $B_{k}^{*}$, as behaviors are flows that tend to be persistent, and are expected to determine health. ${ }^{15}$

Finally, potential mechanisms, $B_{k}$ and $\Theta^{H}$, affect $\lambda(t)$, which is the conditional instantaneous probability of a person's death at time $t($ event $T=t)$ given that a person has survived to that age (event $T>t$ ), where time $t$ is continuous (see Equation (4)). Equation (4) represents a generalization of the continuous-time mixed proportional hazard $(\mathrm{MPH})$ model with a nonparametrically determined baseline hazard function $\lambda_{0}(t)$ (as in the Cox model), in which a number of parameters can change in discrete time $j .{ }^{16,17}$ Discrete time points naturally correspond to ages of and borderline statistically significant complementarity in determining education choice, but not in other aspects of health production.

${ }^{14}$ In Equation (3) we do not need to condition on $\mathbf{X}$, as the latent health stock is defined conditional on $\mathbf{X}$ in Equation (6).

${ }^{15}$ A possible alternative approach to modeling health stock is to make equation (3) more reducedform and omit behaviors $\boldsymbol{B}$. Theoretically, it is unclear which approach is better, but empirically it does not matter for our decomposition analysis, as our decompositions are robust to restricting $c_{4 k}$ to zero, as we show in Tables A-2 and A-3 described in the Web Appendix.

${ }^{16}$ See Asparouhov et al. (2006) for a detailed discussion of this generalization. Allowing time dependence for only a sub set of model parameters makes this complex model more parsimonious, as discussed in Web Appendix B.

${ }^{17}$ The MPH model accounts for right censoring. Bijwaard et al. (2015) argue that in their sample of a 1937-1941 Dutch cohort it is important to account for left truncation in addition to right censoring. 
survey follow-ups. ${ }^{18}$ The hazard function depends on potential mechanisms, $\boldsymbol{B}$ and $\Theta^{H}$, measured at the beginning of the risk period $(t=0)$. We also allow for direct effects of education and skills, which may be determinants of unobserved mechanisms, just as they are for the observed ones.

In the recursive system (1-4), the unobserved variation is modeled by three components: (1) latent skills, $\Theta^{S}$; (2) other unobserved heterogeneity, $\boldsymbol{\mu}=\left(\mu_{D}, \mu_{B 1}, \ldots\right.$, $\left.\mu_{B K}, \mu_{H}, \mu_{\lambda 1}, \mu_{\lambda 2}\right) ;$ and (3) an idiosyncratic error term, $\epsilon$.

Latent skills $\Theta^{S}$ are defined below by a factor model (5), while unobserved heterogeneity $\boldsymbol{\mu}$ is based on a semi-parametric heterogeneity model (Heckman and Singer, 1984). Random variable $\mu$ takes on discrete values $\mu_{1}, \ldots, \mu_{q^{m a x}}$, with probabilities $p_{q}$, such that $\sum_{q=1}^{q^{m a x}} p_{q}=1$. Values $\mu_{1}, \ldots, \mu_{q} \max$ are allowed to differ from equation to equation in System (1-4), while probabilities $p_{q}$ are common across the system for each individual and are interpreted as probabilities for that individual to belong to a specific latent class $q$ of individuals. Discrete values of $\mu_{q}$ and probabilities $p_{q}$ are model parameters to be estimated. The number of latent classes $q^{\max }$ is determined from practical considerations of the best fit and empirical identification (e.g., Cameron and Trivedi, 2005). In this paper we determine that $q^{\max }=3$ for both men and women, as $q^{\max }=3$ minimizes both AIC and BIC of the model However, our sample is different. In particular, all WLS subjects have at least a high school degree, while in the Dutch sample only a half of subjects graduated from high school. Less than $4 \%$ of the WLS sample died before 1993. Moreover, we do not find any evidence of selective survival to year 1993 by skills, IQ, or post-compulsory education (see Table A-1 of the Web Appendix).

${ }^{18}$ Due to practical considerations described in Sections II and IV, we set $J=2$ and $K=8$. Index $J$ changes from 1 to 2 at $t=12$ years after the start of the risk period ( $t=0$ at the start of 1993, which corresponds to approximately age 53.). 
(Nylund et al., 2007). ${ }^{19}$ We make standard normalizations to avoid indeterminacy: $\left(\mu_{H 1} \mid Q=1\right)=0 ;\left(\mu_{\lambda j} \mid Q=1\right)=0$ for $j=1,2$; and $\operatorname{Var}\left(\epsilon_{H 1} \mid Q=q\right)=1$, for each $q=1, \ldots, q^{\max }$, where $Q$ is a random latent class variable.

Our accounting for unobserved heterogeneity can be expected to yield accurate results. Heckman and Singer (1984) have shown that finite mixtures with a small number of points of support ( $2-5$ points) are sufficiently flexible for the purpose of approximating unobserved heterogeneity in duration models and that this method leads to accurate estimates of parameters and predictions of durations despite less accurate estimates of the mixing distribution. Mroz (1999) shows that the use of finite mixtures leads to accurate estimates of parameters in recursive models with binary endogenous variables.

The Measurement System The measurement system links latent skills $\Theta^{S}$ and health $\Theta^{H}$ to their noisy dedicated measures $\boldsymbol{M}$ and $\boldsymbol{H}$ :

$$
\begin{aligned}
& M_{l}{ }^{*}=\alpha_{0 l}+\boldsymbol{\alpha}_{1 l} \boldsymbol{X}+\alpha_{2 l} \Theta^{S}+\eta_{M l}, l \in 1, \ldots, l^{\max } \\
& H_{m}{ }^{*}=\beta_{0 m}+\boldsymbol{\beta}_{1 m} \boldsymbol{X}+\beta_{2 m} \Theta^{H}+\eta_{H m}, m \in 1, \ldots, m^{\max },
\end{aligned}
$$

where $\alpha_{0 l}$ and $\beta_{0 m}$ denote the intercepts, $\boldsymbol{\alpha}_{1 l}$ and $\boldsymbol{\beta}_{1 m}$ are vectors of coefficients, $\alpha_{2 l}$ and $\beta_{2 m}$ are factor loadings, and $\eta_{M l}$ and $\eta_{H m}$ are zero-mean error terms, which explicitly model the noise in measures $\boldsymbol{M}$ and $\boldsymbol{H}$. For binary measures we use

\footnotetext{
${ }^{19}$ See Table A-4 in the Web Appendix for AIC and BIC as a function of the number of latent classes.
} 
logit models. For continuous measures, $M_{l}^{*}=M_{l}$ and $M_{m}^{*}=M_{m}$. Measures $M$ of performance in high school are documented in Table $1 .{ }^{20}$ Measures $\boldsymbol{H}$ of physical health are shown in Table 2.

We use a standard assumption that error terms $\eta_{M l}$ and $\eta_{H m}$ are mutually uncorrelated and also uncorrelated with latent factors. Terms $\eta_{M l}$ are also uncorrelated with error terms in the recursive system. However, latent factors may correlate among themselves. For identification, we normalize the variance of latent skills and the residual variance of latent health stock to one, so that $\operatorname{Var}\left(\Theta^{S} \mid Q=q\right)=1$ and $\operatorname{Var}\left(\epsilon_{H} \mid Q=q\right)=1$ for $q=1, \ldots, q^{\max }$. Coefficients $\alpha_{21}$ and $\beta_{21}$ are set to be positive, which makes the latent factors interpretable as skills and health, rather than negative skills and sickness without loss of generality.

The Multinomial Logit Model When modeling unobserved heterogeneity we relax the common assumption (e.g., van den Berg, 2001) that unobserved heterogeneity is orthogonal to all background controls. To do so, we link probabilities $p_{q}$ of latent classes $q$ to latent skills $\Theta^{S}$ and a number of essential observables $Z .^{21}$ As a result, the probabilities of latent classes become person-specific and correlated

\footnotetext{
${ }^{20}$ One can argue that achievement may depend on school quality: for the same level of IQ and noncognitive skills it may be harder to be in the same achievement percentile at a more prestigious school. However, controlling for school quality should minimize the issue. We control for major predictors of school quality including parental earnings, education, and occupation; rural area, town, metropolitan area, and others.

${ }^{21}$ In our case, $\boldsymbol{Z}$ includes IQ and pre-college health behaviors. Theoretically, all variables $\boldsymbol{X}$ can be included in $Z$. However, we have a practical limitation: while the model is robust to inclusion of various sub-sets of $\boldsymbol{X}$, we get issues with numerical stability (convergence) of the model when we include the full set. This is likely an empirical non-identification issue aggravated by our modest sample size.
} 
with key background variables:

$$
\begin{aligned}
p_{q} & =\frac{\exp \left(e_{q 0}+e_{q 1} \Theta^{S}+e_{q 2} \boldsymbol{Z}\right)}{1+\sum_{h=1}^{q^{\max }-1}\left(\exp \left(e_{h 0}+e_{h 1} \Theta^{S}+e_{h 2} \boldsymbol{Z}\right)\right)}, q=1, \ldots, q^{\max }-1 \\
p_{q^{\max }} & =1-\sum_{h=1}^{q^{\max }-1} p_{h}
\end{aligned}
$$

where $e_{q 0}, e_{q 1}$, and $e_{q 2}$ are model coefficients.

Model Identification Identification of the model follows from identification of its standard components. Parameters related to latent factors $\Theta^{S}$ and $\Theta^{H}$ are identified, as each latent factor has at least three dedicated measures in the measurement system $(5,6)$, which is a sufficient condition for identification in a factor model conditional on standard normalizations and the assumptions described above. ${ }^{22}$ Identification of system (1-4) is based on its recursive nature. Maddala (1983) argues that a nonlinear recursive model involving endogenous binary variables is identified as long as background controls are exogenous and error terms are mutually uncorrelated. ${ }^{23}$ Usually, this assumption is too strong, even conditional on $\boldsymbol{X}$, as we expect correlated unobserved heterogeneity to be present in error terms. However, we also condition the model on unobservables. We assume that conditional on detailed controls $\boldsymbol{X}$, latent skills $\Theta^{S}$, and unobserved heterogeneity $\boldsymbol{\mu}$, error terms

\footnotetext{
${ }^{22}$ An alternative estimation method would be calculating factor scores based on the measurement system only and then using them as regressors in the recursive system, but we use a more efficient full likelihood estimation. For details about identification of standard factor models, see Anderson and Rubin (1956). A case with binary measures is analyzed in Muthen (1983).

${ }^{23}$ See discussion on $p p$. 120-123 of Maddala (1983).
} 
$\epsilon_{D}, \epsilon_{H}$, and $\epsilon_{B k}$ are uncorrelated. Finally, identification of a model that has latent classes correlated with covariates is shown by Huang and Bandeen-Roche (2004). The model is supported by placebo tests documented in the Web Appendix. ${ }^{24}$

Limitations We acknowledge that our identification comes at a cost of additional implicit and explicit assumptions. Moreover, we only offer an approximation to unobserved heterogeneity, which cannot be as good as controlling for a full set of unobservable confounders if they were available in the data. Therefore, our results can be conservatively viewed as associations conditional on detailed observables and approximated unobservables. Under this view, our estimates are still informative for both researchers and practitioners, as we rule out a large number of important confounders.

An alternate approach to modeling health and longevity involves estimating a dynamic multi-period rational expectations joint model of investment in college and health over a lifetime. One advantage of this approach is that it would permit future expected shocks to the exogenous variables to alter current decisions. While our approach embodies a human capital framework in which such trade-offs are implicit, it does not permit explicitly measuring the effect of possible future shocks (for example, scientific advances that improve life expectancy) on current decision making. We leave this type of analysis to future research.

\footnotetext{
${ }^{24}$ See Table A-5 and its description in Web Appendix A.
} 
Estimation We use MCMC multiple imputation of missing values (Rubin, 1987; Schafer, 1997) and full information maximum likelihood estimation using the expectationmaximization algorithm. We also employ 100 random starting values of model parameters when estimating our model so that we reach the global maximum of the likelihood function. The result is robust to increasing the number of random starting values to 200 .

Decomposition Our decomposition is in line with both traditional decomposition analysis (Blinder, 1973; Oaxaca, 1973) and with decomposition analysis based on models with latent factors (Heckman, Pinto, and Savelyev, 2013), but is applied to the hazard rate from the MPH model. There are four benefits of this decomposition: (1) It has a clear interpretation, a percentage change in the hazard of death rate when college education dummy changes from zero to one; (2) It can be constructed from estimated model coefficients; (3) Standard errors for all parts of the decomposition can be calculated using the delta method; (4) The decomposition is internally valid and does not require any extrapolation of the baseline survival function or any assumption that model coefficients stay the same beyond the censoring point, which one needs for decomposing life expectancy (which we also do in addition).

To decompose the hazard of death with respect to its mechanisms, we calculate 
the difference in conditional expectations:

$$
\begin{aligned}
& \frac{\Delta \lambda}{\lambda} \approx \mathrm{E}\left\{(\ln (\lambda)) \mid D=\Delta, \boldsymbol{X}, \Theta^{S}, \mu\right\}-\mathrm{E}\left\{(\ln (\lambda)) \mid D=0, \boldsymbol{X}, \Theta^{S}, \mu\right\} \\
& =\underbrace{\left(\sum_{k}\left(d_{4 k}+d_{5} c_{4 k}\right) \tilde{b}_{3 k}+d_{5} c_{3}\right) \Delta}+\underbrace{d_{3} \Delta,}_{\text {unexplained effect }} \\
& \text { total explained effect } \\
& \text { (through observed mechanisms) }
\end{aligned}
$$

where coefficients are defined as in equations $(2-4), \tilde{b}_{3 k}$ is the marginal effect of education on mechanism $B_{1 k}$, and $d_{3}$ is a weighted average of $d_{30}$ and $d_{31} \cdot{ }^{25,26,27}$

The approximation for $\frac{\Delta \lambda}{\lambda}$ in Equation (9) is most accurate for a small change in the share $\Delta$ of college-educated people in the population. The case of $\Delta=1$ approximates the counterfactual for a person who is induced to get a college degree. We present our decomposition results for $\Delta=1$. This aproximation is similar to the exact counterfactual for our data. ${ }^{28}$ As decompositions are proportional to $\Delta$,

\footnotetext{
${ }^{25}$ Here and above, $\tilde{b}_{3 k}=b_{3 k}$ for continuous mechanisms. For binary mechanisms, $\tilde{b}_{3 k}$ is the weighted average of logit marginal effects for each latent class with probabilities of classes used as weights. To facilitate presentation of hazard of death decomposition, we use $d_{3}$, which is the weighted average of $d_{30}$ and $d_{31}$, with weights proportional to corresponding time intervals. When calculating life expectancy, the value of remaining life, and related decompositions, we use the original estimates of $d_{30}$ and $d_{31}$ for corresponding time periods.

${ }^{26}$ This relationship comes from the Taylor approximation.

${ }^{27}$ We provide evidence, which indicates that possible changes in the distribution of unobserved heterogeneity during the risk period, as described in Bijwaard et al. (2015), do not create any practical issues for this population over the risk period that we study. In Web Appendix C we test and do not reject the proportional hazard assumption behind the MPH model. Also, our analysis is conditional on unobserved heterogeneity, as in the unnumbered formula in the bottom of p. 950 by Lancaster (1979).

${ }^{28}$ To see the exact formula for $\Delta=1$ rather than an approximation based on calculus, we can make a simple transformation of the estimated difference in $\log$ hazards. Note that $\frac{\Delta \lambda}{\lambda}=\exp (\ln (\lambda \mid D=1)$ $-\ln (\lambda \mid D=0))-1$. So, if we exponentiate our decomposition and subtract 1 we get the exact formula for $\frac{\Delta \lambda}{\lambda}$. For the relatively small changes that we estimate, the exact and the approximate are close. For instance, the contribution of the reduction in smoking to the reduction in the hazard of death is $-1.3 \%$ for men, and it remains approximately the same $(-1.3 \%)$ in the exact case. The contribution of the increase in health stock is $-8.7 \%$, which is $-8.3 \%$ in the exact case. The total effect of education for men is $-32 \%$, which is $-28 \%$ in the exact case.
} 
results can be easily adjusted to any $\Delta$ of readers' interest.

Survival Function We use estimated parameters of the main model (1-8) to calculate the survival function $\hat{S}(t)$, which we use for estimation and decomposition of life expectancy $\hat{e}$ and the value of remaining life $\hat{V}_{R}$. We offer a technique that blends CDC life expectancy data with the structure of our model in order to allow for reasonable counterfactual analysis in the extrapolated part of the survival function (see Web Appendix D for technical details).

Life Expectancy and the Value of Remaining Life We also estimate effects and decompositions in terms of the expected years of additional life and the value of life at the start of the risk period $(t=0)$. Life expectancy is calculated as follows:

$$
\hat{e}=\int_{0}^{\infty} \hat{S}(t) d t .
$$

For the value of remaining life we follow Murphy and Topel (2006) and calculate

$$
\hat{V}_{R}=\int_{0}^{\infty} \hat{S}(t) \hat{v}(t) e^{-r t} d t,
$$

where $\hat{v}(t)$ is the value of a life-year, using the same beginning of time as in $S(t)$, and $r$ is the discount factor. We use $v(t)$ from Murphy and Topel (2006), adjusted to the updated value of life of 9.1 million USD, which is used by the US Department of Transportation and is in line with economic research (Viscusi, 2013). We also use 
a discount factor of 0.035 as in Murphy and Topel (2006). ${ }^{29}$

Finally, we calculate counterfactual changes in life expectancy and the value of life induced by college education using formulas (10) and (11):

$$
\begin{aligned}
\hat{\Delta}_{e} & =\int_{0}^{\infty}(\hat{S}(t \mid D=1)-\hat{S}(t \mid D=0)) d t \\
\hat{\Delta}_{V R} & =\int_{0}^{\infty}(\hat{S}(t \mid D=1)-\hat{S}(t \mid D=0)) \hat{v}(t) e^{-r} d t .
\end{aligned}
$$

\section{EMPIRICAL RESULTS}

We start with a discussion of survival curves predicted by the model. Then we decompose the effect of education on the hazard of death with respect to meditators.

Figure 2 shows survival curves predicted by the model. We first compare predictions based on our semiparametric model with Kaplan-Meier survival curves, which are nonparametric (see Panel (a)). Model predictions for each sex shown by lines match well with Kaplan-Meier estimates shown by hollow rounds. Panel (a) also demonstrates that connecting our survival curves with survival curves from the CDC at $t=24$ (approximately age 77), a point denoted by a vertical dashed line, leads to a smooth curve with no visible kink at the connection point. This is consistent with CDC mortality data for white men and women in the US being an

\footnotetext{
${ }^{29}$ Note that the calculation of $\Delta V_{R}$ only accounts for induced changes in the survival function $S(t)$, but not in quality of life, which is a component of the value of life year $v(t)$. We leave estimation of $\Delta v(t)$ to future research based on data better fitted to address this question. Our current estimates of $\Delta V_{R}$ should be viewed as evaluations of the additional longevity. Total effects on the value of life are likely even larger, since education tends to increase not only longevity but also determinants of quality of life, such as health and wealth.
} 
Figure 2: Survival Curves Predicted by the Model by Sex and Education

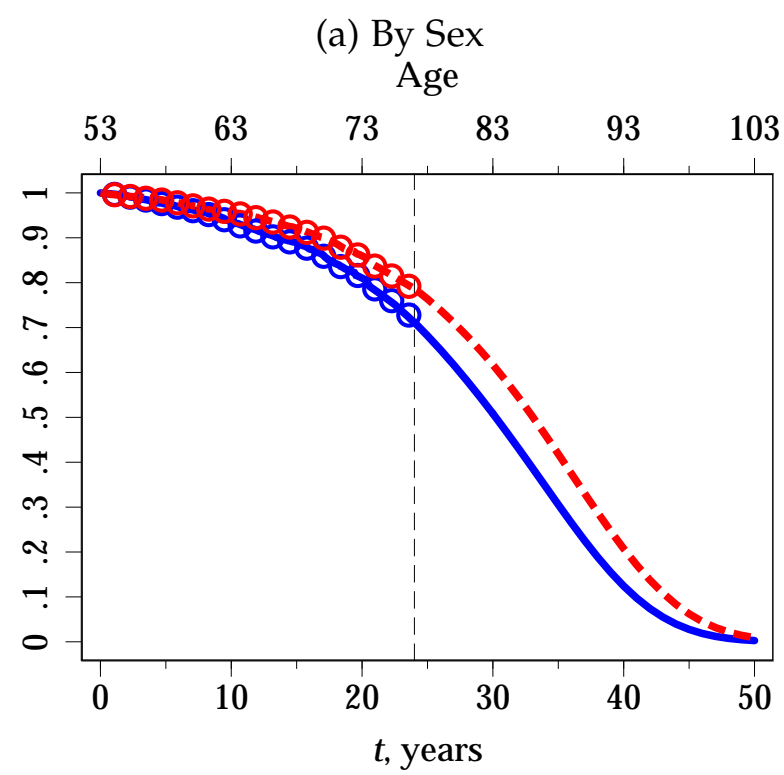

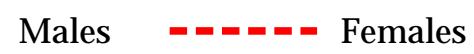

(b) Males

$$
\text { Age }
$$

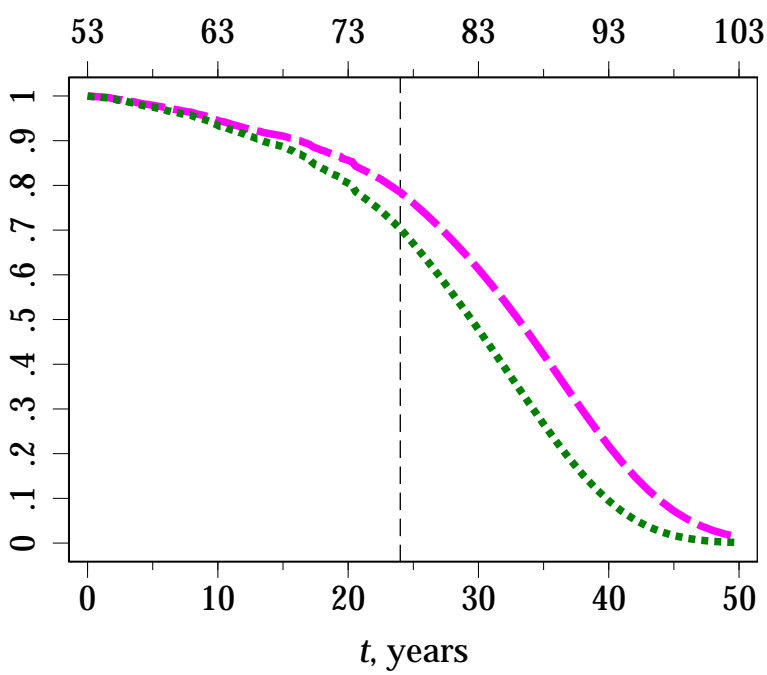

-ーー・ College "......... No College (c) Females, Unadjusted

Age

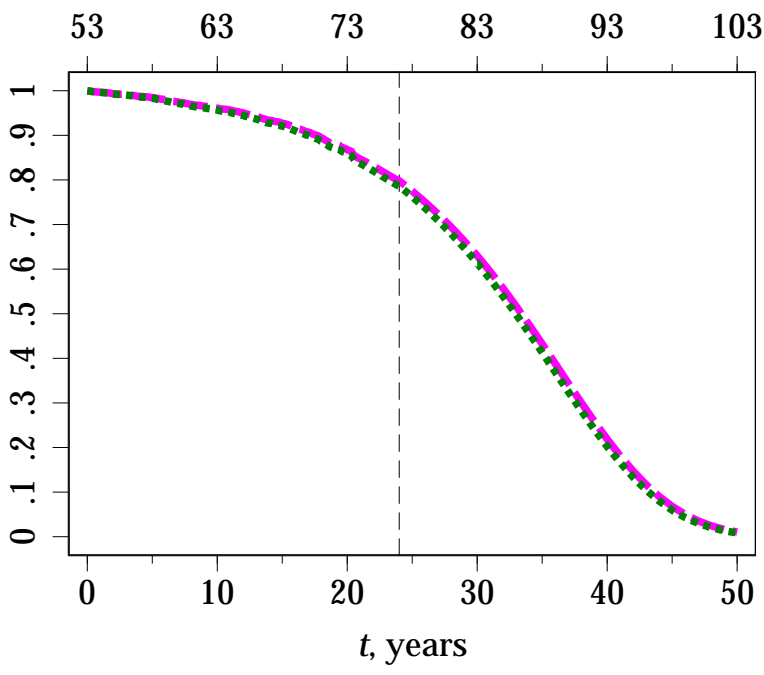

- - College (d) Females, Adjusted

Age

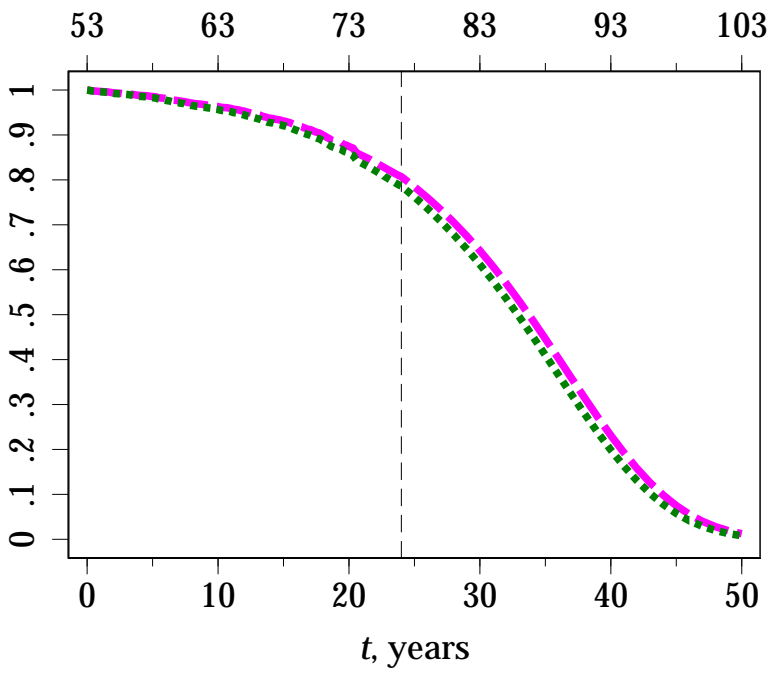

-ーー" College .......... No College

Notes: Hollow rounds in Panel (a) represent Kaplan-Meier survival curves. Vertical dashed lines represent the start of extrapolation. Years axis shows the time from the start of 1993. Age axis shows approximate age, as ages of subjects somewhat differ. Model predictions are calculated based on Formulas (D.1-D.7) presented in the Web Appendix. 
accurate approximation for expected survival of the WLS population.

Panels (b) and (c) show counterfactual predictions of survival curves by education for men and women. ${ }^{30}$ As in Panel (a), our method leads to a smooth overall survival curve in Panels (b) and (c). Panels (a) and (b) show large gaps due to sex and college education in men. Women of this cohort live longer than men, but education is not a big factor in their longevity.

Finally, Panel (d) previews the results of an adjustment, which we discuss in Section V. We recalculate the survival curves for women in the case when education increases the chance of being married in midlife, which it possibly does for a newer generation of women, as opposed to decreasing it, as was the case for the WLS cohort born around 1939. As marriage is beneficial for longevity, we observe a greater distance between survival curves in Section (d) compared to Section (c).

We now turn to our decomposition analysis. We first discuss a decomposition with aggregated results shown in Figure 3 and then proceed with specific mechanisms presented in Figure $4 .{ }^{31}$

Figure 3 shows explained and unexplained components of the effects of education on longevity using decomposition (9). Components due to health behaviors, job-related outcomes, and the health stock sum up to the total explained effect. We add the total explained effect to the total unexplained effect to obtain the total

\footnotetext{
${ }^{30}$ For the risk period $\mathrm{t}=[0,24]$, counterfactual calculations are straightforward. Beyond $t=24$, we offer a counterfactual extrapolation by blending the CDC data with the structure and estimates of our model, as described in Section III (see Equations D.4-D.7).

${ }^{31}$ See Table A-6 for factor loadings estimated for the measurement system and Web Appendix C for estimates of other model parameters that are building blocks of decompositions.
} 
Figure 3: Explained, Unexplained, and Total Effects of Education on the Hazard of Death, \%

(a) Conditional Effects, Males

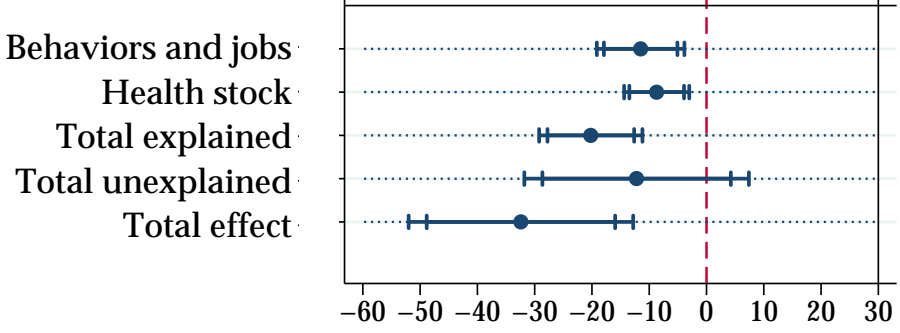

(c) Unconditional Effects, Males

Behaviors and jobs Health stock

Total explained Total unexplained Total effect

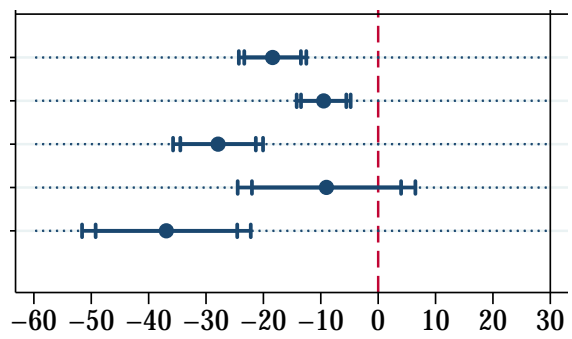

(b) Conditional Effects, Females

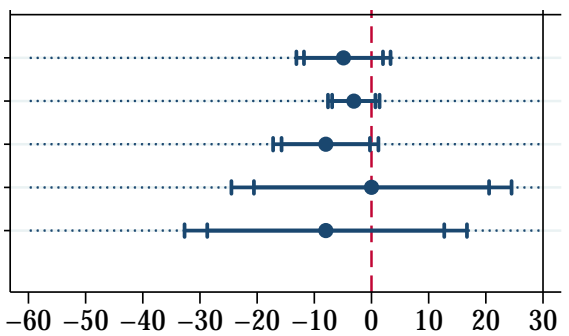

(d) Unconditional Effects, Females

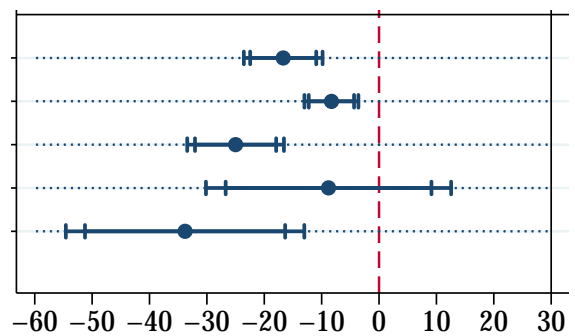

Notes: Panels represent decomposition (9) for $\Delta=1$, with contributions from behavioral and labor market mechanisms aggregated. Conditional effects control for observables $\boldsymbol{X}$, latent skills $\boldsymbol{\Theta}^{S}$, and latent unobserved heterogeneity $\boldsymbol{\mu}$. Unconditional effects control for none of those. Inner and outer vertical bars represent the $90 \%$ and $95 \%$ Huber-White robust confidence intervals. See Table A-1 for tabulated results. Calculations are based on the WLS data.

effect.

The total effect for men is $-32 \%$, implying that the hazard of death is $32 \%$ smaller for college graduates (see Panel (a)). We explain approximately $60 \%$ of the total effect. The total explained effect and the total effect are both statistically significant at the $1 \%$ level. The large contribution of the health stock to the total effect suggests that by age 53 the male cohort has accumulated a substantial difference in the health stock by education, which leads to major differences in the hazard of death (approximately 11\%). 
For women, mechanisms related to observed behaviors and jobs are not precisely determined (see Panel (b)), a feature that we explain below when we analyze specific mechanisms. The total explained effect is statistically significant at the $10 \%$ level. However, as the total unexplained effect has a large standard error, the total effect has a large standard error as well and so it is not precisely determined.

We compare main model results with results of the same model but without controlling for any observables, $\boldsymbol{X}$, or unobservables, $\boldsymbol{\Theta}^{S}$ and $\boldsymbol{\mu}$. We can see that the differences are substantially larger for women than for men. For men, results are statistically significant for both cases, but the numbers differ. For instance, the bias in estimating the contribution of behaviors and jobs in Panel (c) is approximately $60 \%$. The bias for the total effect is approximately $15 \%$. For women, the unconditional case gives strong and statistically significant effects for behaviors and jobs, and the total effect, all of which greatly diminish and become statistically insignificant in the conditional case. This implies stronger selection effects for women than for men.

Figure 4 focuses on the contribution of each specific mechanism, such as smoking tobacco, in explaining the education-longevity gradient. Contributions of specific mechanisms are aggregated into "total explained," which links Figure 4 to Figure 3.

As in Figure 3, we show both conditional (Panels (a) and (b)) and unconditional (Panels (c) and (d)) effects. Unconditional effects tend to be stronger and more precisely determined, suggesting that we control for substantial confounding 
Figure 4: Decompositions of the Effect of Education on the Hazard of Death with Respect to Behavioral and Job-Related Mechanisms, \%

(a) Conditional Effects, Males

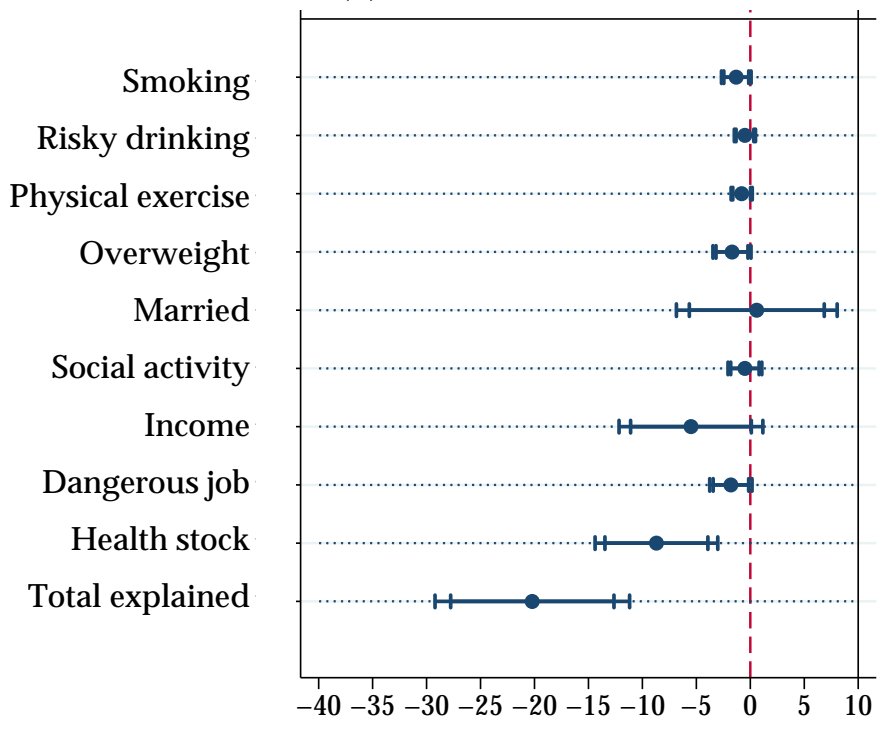

(c) Unconditional Effects, Males

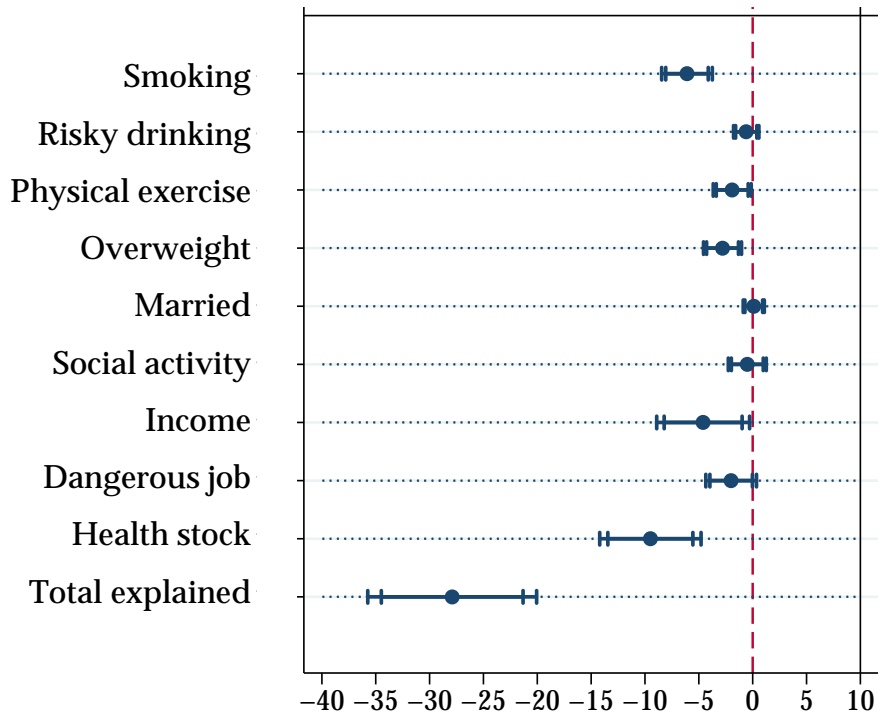

(b) Conditional Effects, Females

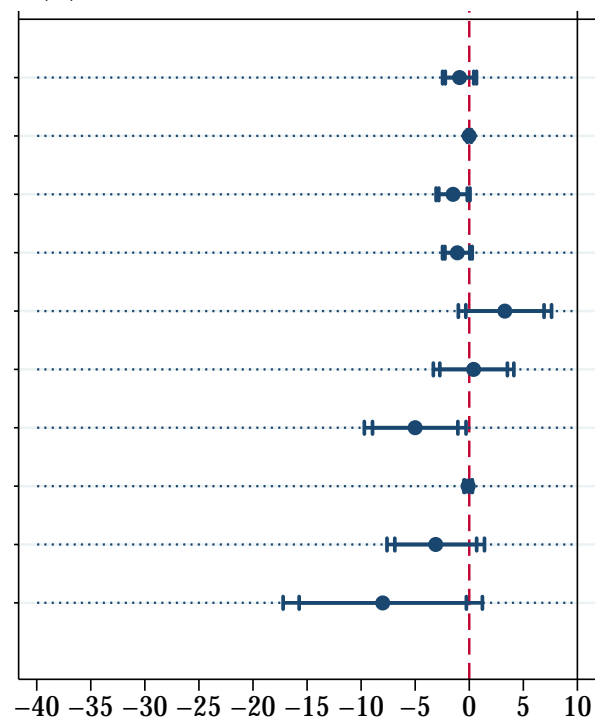

(d) Unconditional Effects, Females

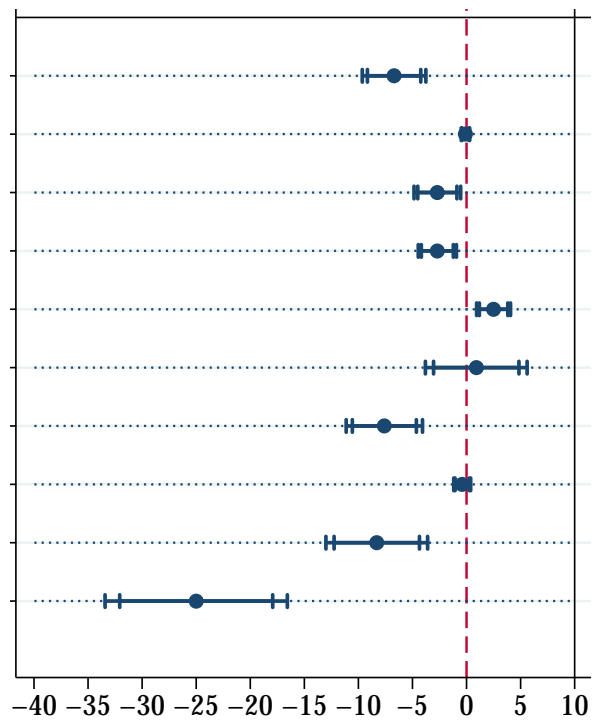

Notes: Panels represent decomposition (9) for $\Delta=1$, focusing on contributions from health behaviors and labor market outcomes. Conditional effects control for observables $\boldsymbol{X}$, latent skills $\Theta^{S}$, and latent unobserved heterogeneity $\boldsymbol{\mu}$. Unconditional effects control for none of those. Inner and outer vertical bars represent the $90 \%$ and $95 \%$ Huber-White confidence intervals. See Table A-1 for tabulated results. Calculations are based on the WLS data. 
variation.

In Panel (a) for men, we see a strong explained effect of approximately $20 \%$ $(p=0.000)$. Statistically significant contributors to this effect include smoking tobacco, being overweight, having a dangerous job, and health stock. Exercise and income are borderline statistically significant.

In Panel (b) for women, the total explained effect is statistically significant at the $10 \%$ level (using a conservative two-tailed test): $p=0.089$. Statistically significant mechanisms are exercise and income. Being overweight and marriage are borderline statistically significant.

Unlike for men, holding a dangerous job is not a mechanism for women. Behind this result there are two findings that are specific for women: (1) no effect of education on holding a dangerous job and (2) no effect of dangerous jobs on longevity. ${ }^{32}$ Perhaps, jobs classified by survey organizers as "extremely dangerous" are, on average, less dangerous for women than they are for men. Sex differences in exactly following safety measures is another possible factor.

As we show in Section $V$, the total explained effect for women would be stronger and more precisely determined $(p=0.002-0.006)$ if not for the adverse contribution of the marriage channel. Overall, for men and women, we see that education affects longevity through a multitude of observed mechanisms.

The model is robust in a number of ways. In particular, the full likelihood model is robust to using an alternative two-step method of estimation, which is expected

\footnotetext{
${ }^{32}$ See Tables C-1 and C-2 of the Web Appendix.
} 
to be more reliable in case of possible model misspecification, where a measurement system for skills is estimated in the first step, and effects of skills on outcomes in the second (Heckman et al., 2016). ${ }^{33}$ Results of this robustness check are consistent with correct model specification. While results are qualitatively robust to various combinations of controls, the quantitative difference is large enough to justify the computationally intensive methods that we employ. For instance, dropping latent controls for unobservables leads to biases of up to $35 \%{ }^{34}$

We evaluate our decompositions also in terms of changes in the years of expected life at age 53 and the corresponding changes in the value of remaining life measured in 2012 USD (see Equations (12) and (13)). We find that the total effect of college education on life expectancy at age 53 for men and women corresponds to 3.3 and 0.49 additional years of life worth 277 and 50 thousand USD, respectively. ${ }^{35}$

A limitation of these life expectancy calculations is that they are less accurate than our main decompositions performed for the estimated age range, shown in Figures 3 and 4. The calculations involve extrapolations to older ages assuming that all regression coefficients of the MPH model stay the same and that the baseline function can be extrapolated using the CDC data on mortality. Further, the monetary valuations of life expectancy changes involve additional assumptions embedded in Murphy and Topel's methodology.

\footnotetext{
${ }^{33}$ See Figure A-1 and the corresponding discussion in the Web Appendix.

${ }^{34}$ Bias refers to the percentage difference in the estimated effect of education on respective components of decompositions when we include all controls versus a subset of controls. See Table A-7 of the Web Appendix.

${ }^{35}$ See Table A-1, which evaluates all decomposition effects in terms of life expectancy and the value of remaining life.
} 


\section{IMPUTATIONS FOR DIFFERENT ENVIRONMENTS AND POLICY IMPLI-} CATIONS

Below we provide simulations that show the effect of changes in environments, both actual and hypothetical.

1. Adjusting for the actual change in the effect of college education on marriage for women and implications for external validity. While our sample of females born around 1939 experienced negative effects of education on the probability of being married, more recent cohorts have had different experiences due to socioeconomic changes in the role of women. Lefgren and McIntyre (2006) present OLS evidence that for cohorts born between 1955 and 1970, female college graduates have a 4.5 percentage points (PP) higher probability of being married in 2000 compared to high school graduates. ${ }^{36}$ The authors' alternative approach is based on using birth quarter as an instrument for education, which leads to a statistically insignificant effect.

Based on these results, we provide two simulations of the total effect of education on the hazard of death for a population in which the marginal effect of education on marriage for women is either 0 or $+4.5 \mathrm{PP}$, as opposed to $-7.6 \mathrm{PP}$ $(p=0.027)$. All other parameters of the model stay the same.

We find that the total explained effect of college education on the hazard of

\footnotetext{
${ }^{36}$ We sum up the changes in the probability of being married in Figure 1 of Lefgren and McIntyre (2006): those with some college credits relative to high school graduates (approximately 0.6 PP), and college graduates relative to those with some college credits (approximately $3.9 \mathrm{PP}$ ).
} 


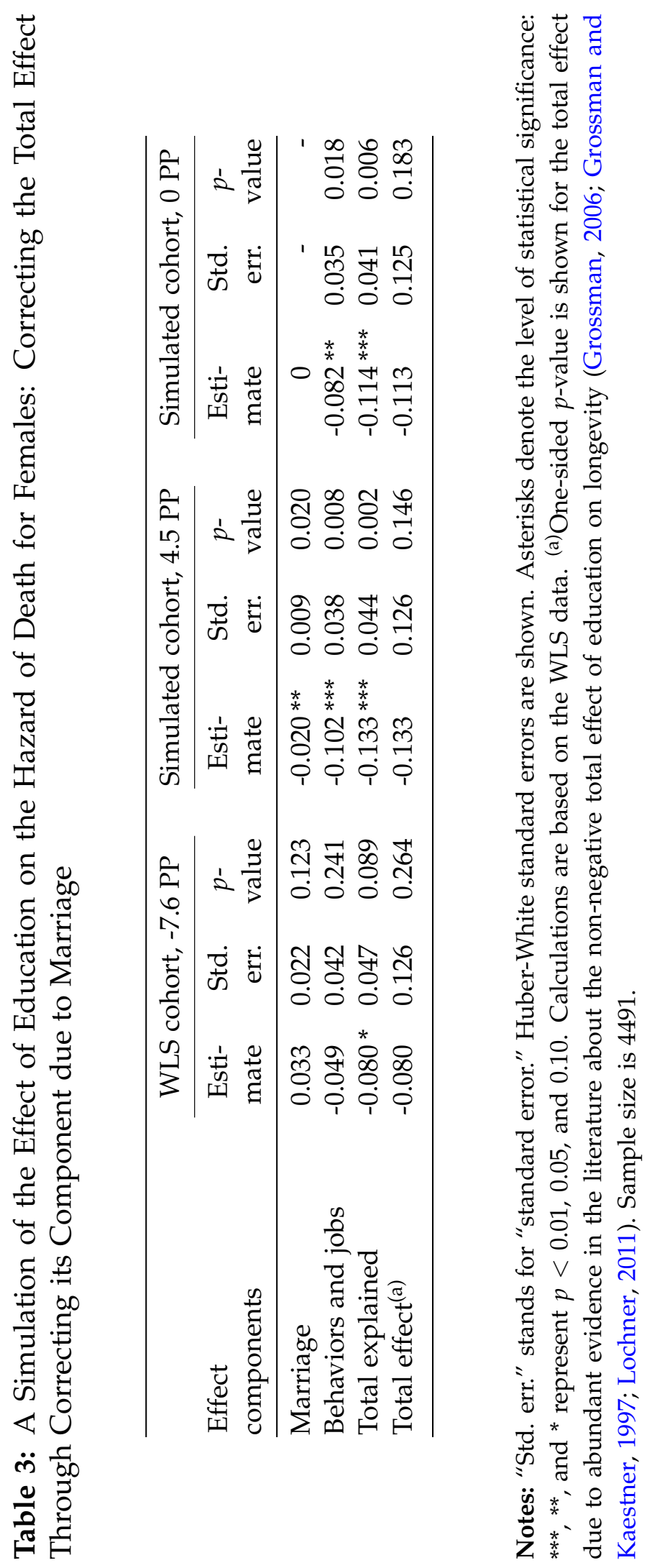


death for women increases from $8 \%(p=0.089)$ to $11 \%(p=0.006)$ if zero effect is assumed and to $13 \%(p=0.002)$ if a $4.5 \mathrm{PP}$ effect is assumed (see Table 3$)$. Since the estimate of the unexplained effect for women is close to zero but has large standard error, estimates for the total effect are the same as for the explained affect, but standard errors are higher. The adjustment leads to a borderline statistically significant total effect $(p=0.146)$. Our finding suggests that the education-mortality gradient for more recent cohorts of women, who no longer experience a negative relationship between marriage and education, is likely to be larger than the estimated effects for the WLS cohort.

The main limitation of this adjustment is a consequence of simultaneous measurement of longevity mechanisms, which prevents us from modeling how a change in one mechanism cause changes in others. Marriage has been linked to multiple health behaviors and lifestyles, although findings are mixed as to whether it is beneficial or harmful. ${ }^{37}$ Overall, our adjustment is probably an underestimate, since marriage is linked to higher household income for women, as shown by Lefgren and McIntyre (2006), and household income is among the strongest observable mechanisms, as we see in Figure 4.

2. Adjusting for hypothetical changes in the taxation of tobacco and policy implications. Our estimates also allow us to analyze how hypothetical changes in environments change the estimated effects. Since smoking is a major mechanism, we provide

\footnotetext{
${ }^{37}$ Wood et al. (2007) provide a detailed survey of the most statistically-rigorous studies relating marriage and health-related outcomes. They report that marriage is linked with a lower cost of health care among older adults but also with reduced physical activity and modest weight gain. Evidence for the effect on smoking is mixed.
} 
an example of a hypothetical additional tax on tobacco products and its role as a policy intervention aimed at reducing the health inequality caused by education, among other policy goals.

A change in tobacco taxes will change average smoking levels by (price elasticity) $\times(\%$ tax $) \times($ average smoking level $)$. We apply this change to counterfactual average levels of smoking of college graduates and non-graduates using the median estimated price elasticity of smoking participation in the literature, -0.5 (Gallet and List, 2003). ${ }^{38}$

We find that an increase in the tobacco tax rate as large as 50\% would reduce the college education-longevity gradient only by $1 \%$ for men and $3 \%$ for women. ${ }^{39}$ There is no contradiction between a strong effect of smoking on longevity and a weak effect obtained in this imputation, as here we estimate a difference in effects by education level.

Our analysis on tobacco taxes has several important caveats, although we believe the exercise is still informative. One issue is that changes in smoking behavior in response to a tobacco tax may be more complex than a change in the probability of ever smoking. For instance, smokers may respond by changing the intensity of smoking yielding improvements to mortality that are not captured in our estimates (Adda and Cornaglia, 2013). Alternatively, there may be spillover effects of smok-

\footnotetext{
${ }^{38}$ It is unlikely that price elasticities differ much by education level (Gruber and Koszegi, 2004).

${ }^{39}$ This corresponds to 2.1 weeks of additional life for men and 1.2 weeks for women compared to the total college education-longevity gap of 3.3 years for men and 0.8-0.9 years for women (using the marriage-adjusted total for women). Effects of education are precisely determined for men but not for women, and so tax effect comparisons for women should be interpreted with caution.
} 
ing on obesity (Wehbya and Courtemanche, 2012). However, our numbers suggest that these possible omitted effects would have to be very large to change our main result: even a major increase in the taxation of tobacco would have only a minor contribution to closing the education-longevity gap.

3. Implications of results discussed above for human capital enhancement policies. The poor health of disadvantaged populations, as well as the related health gap between people from advantaged and disadvantaged backgrounds, are major policy concerns. Low parental socio-economic status often translates into low skill and education levels of children and results in major health inequality (Heckman, 2008). As our tobacco tax example shows, this gap is not easy to close as late as in midlife, even with a heavy-handed approach aimed at a major observed mechanism of mortality.

\section{DISCUSSION}

We now discuss our contributions in more detail: decomposing the educationlongevity gradient, bolstering support for a causal link between education and longevity, explaining heterogeneity in the education-health gradient by sex, and using the framework to perform policy counterfactuals.

The Mechanisms Linking Education and Longevity The literature suggests that health behaviors as a whole likely are important mechanisms, but numerical contributions of specific mechanisms are unclear and evidence is often suggestive. 
Buckles et al. (2016) and Savelyev (2020) support their claim that college education negatively affects male mortality by showing that education also affects a number of health behaviors, but they do not quantify the contribution of each of these behaviors to the education-mortality gradient. Cutler, Lleras-Muney, and Vogl (2011) regress 10-year mortality dummies on education and find that including health behaviors as controls attenuates the education coefficient by $40 \%$, but they do not identify the contributions of specific health behaviors and do not control for unobserved heterogeneity. Aggregated contributions estimated by the authors are specific to the particular mix of health behaviors available in the data. Balia and Jones (2008) use British data to decompose the Gini coefficient for mortality with respect to multiple determinants and find that accounting for observed lifestyles and health behaviors decreases education's contribution to the total Gini coefficient by $72 \%$.

Contoyannis and Jones (2004) and Brunello et al. (2015) explore the mediating role of health behaviors for the education-health gradient. Our work resembles that of Contoyannis and Jones (2004), as we also model unobserved heterogeneity that affects outcomes in a recursive system of equations. However, the method that we use for modeling unobserved heterogeneity $\boldsymbol{\mu}$ is nonparametric and does not rely on multivariate normal distribution assumption.

We support the claim made in these two papers that health behaviors are important mediators linking education with health, but we concentrate on explaining longevity. Longevity is arguably the most long term outcome, and it suffers less 
from potentially underestimating of the impact of education and mediators on health (Lochner, 2011). Further, although self-reported general health is an informative and widely used summary of health status, longevity is an objective measure. In addition, unlike the previous studies, we control for early IQ measures and skills, which are known to be major confounders. Lastly, our paper studies effects of college education whereas Brunello et al. (2015) study effects of an additional year of compulsory schooling.

We also estimate a model using health stock in 2011 instead of hazard of death as the final outcome. ${ }^{40}$ Results of this model can be more directly compared with results by Contoyannis and Jones (2004) and Brunello et al. (2015). This model is not our main contribution, but rather a supplemental exercise that helps link our paper to the literature. We find an effect of college education on health for men and women. As in Contoyannis and Jones (2004) and Brunello et al. (2015), behavioral mediators explain a part of the total effect: effects due to behavioral mediators are statistically significant for women and are borderline statistically significant for men. For women, we identify such individual contributions as exercise, overweight, and income. We also see that our longevity decomposition gives us more detailed decomposition results than our results for health stock as an outcome, which is an empirical support of the theoretical advantages of modeling longevity rather than health.

Overall, we view our study as providing a more detailed decomposition than

\footnotetext{
${ }^{40}$ See table A-8 of Web Appendix A
} 
has been offered in the literature, for a less studied education effect (namely college), and for the longest-term and more objective outcome (longevity).

Causal Status of the Relationship between Education and Longevity The causal status of the effect of education on longevity is a major question in both theory and policy (Grossman, 2000). Results, however, are controversial.

The most common instrumental variable, which is based on changes in compulsory schooling laws, leads to mixed results. ${ }^{41}$ The results differ partly because of the weakness of this instrument for a number of countries, including the USA, and partly because of likely differences in effects by country, sex, and cohort.

Results based on twin fixed effects are controversial as well. ${ }^{42}$ Possible reasons for this controversy include measurement error issues, differences in model specification, and likely differences in effects by population.

A third established approach to account for endogeneity of schooling is a direct modelling of unobserved confounders using structural assumptions (Bijwaard, van Kippersluis, and Veenman, 2015; Conti and Heckman, 2010; Savelyev and Tan, 2019). This literature typically finds the effect of education on health and longevity (see Grossman (2015) for a review.) This paper contributes to this literature by combining a comprehensive modeling of unobservables with a decomposition analysis

\footnotetext{
${ }^{41}$ For instance Lleras-Muney (2005) and van Kippersluis et al. (2011) find a strong effect of education on health-related outcomes, while Arendt (2005), Mazumder (2008), Meghir et al. (2018), Albouy and Lequien (2009), and Clark and Royer (2013) find no effect.

${ }^{42}$ For instance, Madsen et al. (2010), Behrman et al. (2011), and Amin et al. (2015) find no effect, while other researchers find a strong effect (Lundborg et al., 2016; Savelyev et al., 2020; van den Berg et al., 2015).
} 
of the hazard of death's education gradient.

Finally, causal effects of education (if they exist) may differ by education threshold, and only a few studies identify the effect of a college degree. We know of only two studies regarding the effect of college education on longevity: Buckles et al. (2016), who use the Vietnam war draft as an instrument, and Savelyev (2020), who directly models unobserved confounders. Even though both studies affirm the positive link between college education and longevity, more evidence is needed, especially given that Buckles et al. (2016) study only men, while Savelyev (2020) studies a specific population with IQ's above 140. Our positive results for the effect of college education on longevity therefore complement the relatively thin literature on this subject.

Sex Difference in the Effect of Education on Longevity A number of studies find effects of education on longevity for men but not for women (e.g., van den Berg et al. (2015), Fischer et al. (2013), Savelyev et al. (2020)). Our decomposition analysis partly explains the sex difference. Like for men, education boosts a number of longevity mechanisms for women. Unlike for men, college education for women historically contributed to a lower likelihood of staying married. For both men and women, marriage is known to benefit longevity (Manzoli et al., 2007). For women, the negative effect on longevity through marriage partly cancels the positive effect through other mechanisms leading to a smaller total effect of education on longevity. The increasing education-longevity gradient for women documented 
by Cutler et al. (2011) over the last few decades could be partly explained by the change in relationship between women's education and marriage.

Policy Simulations and Other Advantages of the Model Finally, as seen in our policy counterfactuals, our model allows for adjustments of the estimated effect to different environments. Adjusting to different environments is beyond the reach of a traditional treatment effect approach when a natural (or randomized) experiment is used to calculate causal effects without explicitly modeling the mechanisms that underlie them (Heckman and Vytlacil, 2007). Another advantage of the model is that we do not rely on instrumental variables to answer research questions that would require many instrumental variables for identification. Finding a dozen strong and valid instruments is hardly realistic even in the most detailed survey. ${ }^{43}$

\section{CONCLUSIONS}

We explore a large number of behavioral mechanisms that together explain a sizable portion of the effect of college education on longevity. Conflicting mediation effects of education for women contribute to our understanding of the historic sex gap in the effect of education on longevity. These findings are consistent with the rising education-longevity gradient for women documented in the literature.

In addition, our counterfactuals suggest that the education-longevity gap is not

\footnotetext{
${ }^{43}$ Generally, in a mediation study based on instrumental variables, a researcher needs instrumental variables to identify the effect of treatment on mechanisms plus instrumental variables to identify the effect of each mechanism on the final outcome. With an increasing number of mechanisms the likelihood of finding enough instruments for identification diminishes greatly. This study involves nine potential mechanisms.
} 
amenable to being eliminated by targeting any single mechanism in midlife with policy interventions. We focus on smoking as an example because the policy intervention (tobacco taxes) is clear and historically relevant, and because smoking is a major mechanism. We show that even an exceptionally high tobacco tax would do little to flatten the education-longevity gradient.

This paper shows that education increases longevity through healthier lifestyles, superior earnings, and better work conditions. Uncovering these mechanisms reinforces the evidence for causal links between education and longevity. The nondominant role of income and job conditions highlights the importance of health behavior choices. Identifying these mechanisms opens the door for modeling and predicting the effects of education on longevity for different economic environments.

\section{References}

Adda, J. and F. Cornaglia (2013). Taxes, cigarette consumption, and smoking intensity: Reply. The American Economic Review 103, No 7, pp. 3102-3114.

Aitken, M. and D. B. Rubin (1985). Estimation and hypothesis testing in finite mixture models. Journal of Royal Statistical Society, Series B 47 (1), pp. 67-75.

Albouy, V. and L. Lequien (2009). Does compulsory education lower mortality? Journal of Health Economics 28, 155-168.

Almlund, M., A. L. Duckworth, J. J. Heckman, and T. Kautz (2011). Personality psychology and economics. In E. A. Hanushek, S. Machin, and L. Wößmann (Eds.), Handbook of the Economics of Education, Volume 4, Chapter 1, pp. 1-181. Amsterdam: Elsevier B. V.

Amin, V., J. R. Behrman, and H.-P. Kohler (2015). Schooling has smaller or insignificant effects on adult health in the US than suggested by cross-sectional 
associations: New estimates using relatively large samples of identical twins. Social Science E Medicine 127, 181-189.

Anderson, T. W. and H. Rubin (1956). Statistical inference in factor analysis. In J. Neyman (Ed.), Proceedings of the Third Berkeley Symposium on Mathematical Statistics and Probability, Volume 5, Berkeley, CA, pp. 111-150. University of California Press.

Arendt, J. N. (2005). Does education cause better health? A panel data analysis using school reforms for identification. Economics of Education Review 24(2), 149160.

Asparouhov, T., K. Masyn, and B. Muthen (2006). Proceedings of the Joint Statistical Meeting in Seattle, August 2006. In ASA Section on Biometrics, pp. 180-187.

Balia, S. and A. Jones (2008). Mortality, lifestyle, and socio-economic status. Journal of Health Economics 27, 1-26.

Bayne-Jones, S., W. J. Burdette, W. G. Cochran, E. Farber, L. F. Fieser, J. Furth, J. B. Hickam, C. LeMaistre, L. M. Schuman, and M. H. Seevers (1964). Smoking and health: Report of the Advisory Committee to the Surgeon General of the United States. Public Health Service publication No. 1103. Technical report, Department of Health, Education, and Welfare.

Behrman, J. R., H.-P. Kohler, V. M. Jensen, D. Pedersen, I. Petersen, P. Bingley, and K. Christensen (2011). Does more schooling reduce hospitalization and delay mortality? New evidence based on Danish twins. Demography (48), 1347-1375.

Belfield, C. R. and I. R. Kelly (2012). The benefits of breastfeeding across the early years of childhood. Journal of Human Capital 6(3), 251-277.

Bijwaard, G., H. van Kippersluis, and J. Veenman (2015). Education and health: The role of cognitive ability. Journal of Health Economics 42, 29-43.

Blinder, A. S. (1973). Wage discrimination: Reduced form and structural estimates. Journal of Human Resources 8(4), 436-455.

Brunello, G., M. Fort, N. Schneeweis, and R. Winter-Ebmer (2015). The causal effect of education on health: What is the role of health behaviors. Health Economics, 314-336.

Buckles, K., A. Hagemann, O. Malamud, M. Morrill, and A. Wozniak (2016). The effect of college education on mortality. Journal of Health Economics 50, 99-114.

Cameron, A. C. and P. K. Trivedi (2005). Microeconometrics: Methods and Applications. New York: Cambridge University Press. 
Clark, D. and H. Royer (2013). The effect of education on adult mortality and health: Evidence from Britain. American Economic Review 103(6), 2087-2120.

Conti, G. and J. J. Heckman (2010). Understanding the early origins of the education-health gradient: A framework that can also be applied to analyze gene-environment interactions. Perspectives on Psychological Science 5(5), 585-605.

Conti, G., G. Mason, and S. Poupakis (2019, August). Developmental origins of health inequality. The Oxford Research Encyclopedia, Economics and Finance (oxfordre.com/economics), 1-88.

Contoyannis, P. and A. M. Jones (2004). Socio-economic status, health, and lifestyle. Journal of Health Economics 23, 965-995.

Cutler, D. M., F. Lange, E. Meara, S. Richards-Shubik, and C. J. Ruhm (2011). Rising Educational Gradients in Mortality: The Role of Behavioral Risk Factors. Journal of Health Economics 30(6), 1174-1187.

Cutler, D. M., A. Lleras-Muney, and T. Vogl (2011). Socioeconomic status and health: Dimensions and mechanisms. In S. Glied and P. Smith, eds the Oxford Handbook of Health Economics.

Ehrlich, I. and Y. Yin (2013). Equilibrium Health Spending and Population Aging in a Model of Endogenous Growth: Will the GDP Share of Health Spending Keep Rising. Journal of Human Capital 7(4), 411-447.

Farrell, P. and V. R. Fuchs (1982). Schooling and health: the cigarette connection. Journal of Health Economics 1(3), 217-230.

Fischer, M., M. Karlsson, and T. Nilsson (2013). Effects of compulsory schooling on mortality: Evidence from Sweden. Int. J. Environ. Res. Public Health.

Galama, T. J., A. Lleras-Muney, and H. van Kippersluis (2018, September). The effect of education on health and mortality: A review of experimental and quasiexperimental evidence. The Oxford Research Encyclopedia, Economics and Finance (oxfordre.com/economics), 1-96.

Gallet, C. A. and J. A. List (2003). Cigarette demand: a meta-analysis of elasticities. Health Economics 12, 821-835.

Gilleskie, D. (2014). Encyclopedia of Health Economics, Volume 1, Chapter "Dynamic models: econometric considerations of time", pp. 209-216. Elsevier Inc.

Goldin, C. (1997). Career and family: College women look to the past. In F. Blau and R. Ehrenberg (Eds.), Gender and Family Issues in the Workplace, pp. 20-58. Russell Sage Press, New York. 
Grossman, M. (2000). The human capital model. In A. J. Culyer and J. P. Newhouse (Eds.), Handbook of Health Economics, Volume 1, Chapter 7, pp. 347-408. Amsterdam: Elsevier Science B. V.

Grossman, M. (2006). Education and nonmarket outcomes. In E. Hanushek and F. Welch (Eds.), Handbook of the Economics of Education, Volume 1, Chapter 10, pp. 577-633. Amsterdam: Elsevier.

Grossman, M. (2015). The relationship between health and schooling: What's new? Nordic Journal of Health Economics 3(1), 7-17.

Grossman, M. and R. Kaestner (1997). Effects of education on health. In J. R. Behrman and N. Stacey (Eds.), The Social Benefits of Education, pp. 69-124. Ann Arbor, MI: University of Michigan Press.

Gruber, J. and B. Koszegi (2004). Tax incidence when individuals are timeinconsistent: the case of cigarette excise taxes. Journal of Public Economics 88, 1959-1987.

Hauser, R. M. and W. H. Sewell (1957-2005). Wisconsin Longitudinal Study (WLS) [graduates, siblings, and spouses]: 1957-2005 Version 13.01.

Heckman, J. J. (2008, July). Schools, skills, and synapses. Economic Inquiry 46(3), 289-324.

Heckman, J. J., J. E. Humphries, and G. Veramendi (2016). Returns to education: The causal effects of education on earnings, health and smoking. Forthcoming, Journal of Political Economy.

Heckman, J. J., R. Pinto, and P. A. Savelyev (2013). Understanding the mechanisms through which an influential early childhood program boosted adult outcomes. American Economic Review 103(6), 2052-2086.

Heckman, J. J. and B. S. Singer (1984, March). A method for minimizing the impact of distributional assumptions in econometric models for duration data. Econometrica 52(2), 271-320.

Heckman, J. J., J. Stixrud, and S. Urzúa (2006, July). The effects of cognitive and noncognitive abilities on labor market outcomes and social behavior. Journal of Labor Economics 24(3), 411-482.

Heckman, J. J. and E. J. Vytlacil (2007). Econometric evaluation of social programs, part I: Causal models, structural models and econometric policy evaluation. In J. J. Heckman and E. E. Leamer (Eds.), Handbook of Econometrics, Volume 6B, Chapter 70, pp. 4779-4874. Amsterdam: Elsevier B. V. 
Herd, P., D. Carr, and C. Roan (2014). Cohort Profile: Wisconsin Longitudinal Study (WLS). International Journal of Epidemiology 43, 34-41.

Huang, G.-H. and K. Bandeen-Roche (2004, Mar). Building an identifiable latent class model with covariate effects on underlying and measured variables. Psychometrika 69(1), 5-32.

Lancaster, T. (1979, July). Econometric methods for the duration of unemployment. Econometrica 47(4), 939-956.

Lefgren, L. and F. McIntyre (2006). The Relationship between Women's Education and Marriage Outcomes. Journal of Labor Economics 24, 787-830.

Lleras-Muney, A. (2005). The relationship between education and adult mortality in the United States. Review of Economic Studies 72(1), 189-221.

Lochner, L. (2011, January). Non-production benefits of education: Crime, health, and good citizenship. Working Paper 16722, National Bureau of Economic Research.

Lundborg, P., C. H. Lyttkens, and P. Nystedt (2016). The effect of schooling on mortality: New evidence from 50,000 Swedish twins. Demography (53), 11351168.

Maddala, G. (1983). Limited-Dependent and Qualitative Variables in Econometrics. New York: Cambridge University Press.

Madsen, M., A.-M. N. Andersen, K. Christensen, P. K. Andersen, and M. Osler (2010). Does educational status impact adult mortality in Denmark? A twin approach. American Journal of Epidemiology 172, 225-234.

Manzoli, L., P. Villari, G. M. Pirone, and A. Bocca (2007). Marital status and mortality in the elderly: A systematic review and meta-analysis. Social Science and Medicine 64, 77-94.

Mazumder, B. (2008). Does education improve health? A reexamination of the evidence from compulsory schooling laws. Economic Perspectives 32(2), 2-16.

Meghir, C., M. Palme, and E. Simeonova (2018, April). Education and mortality: Evidence from a social experiment. American Economic Journal: Applied Economics 10(2), 234-56.

Mroz, T. A. (1999). Discrete factor approximation in simultaneous equation models: Estimating the impact of a dummy endogenous variable on a continuous outcome. Journal of Econometrics 92(2), 233-274. 
Murphy, K. M. and R. H. Topel (2006, October). The value of health and longevity. Journal of Political Economy 114(5), 871-904.

Muthen, B. (1983). Latent variable structural equation modeling with categorical data. Journal of Econometrics 22, 43-65.

Nylund, K. L., T. Asparouhov, and B. O. Muthen (2007). Deciding on the number of classes in latent class analysis and growth mixture modeling: A Monte Carlo simulation study. Structural Equation Mod 14(4), 535-569.

Oaxaca, R. L. (1973). Male-female wage differentials in urban labor markets. International Economic Review 14(3), 693-709.

Rubin, D. (1987). Multiple Imputation for Nonresponse in Surveys. New York: J. Wiley \& Sons.

Savelyev, P. A. (2020). Conscientiousness, Extraversion, college education, and longevity of high-ability individuals. SSRN Working Paper http://dx.doi. org/10.2139/ssrn.1715942.

Savelyev, P. A. and K. T. Tan (2019). Socioemotional skills, education, and healthrelated outcomes of high-ability individuals. American Journal of Health Economics 5, pp. 250-280.

Savelyev, P. A., B. Ward, R. Krueger, and M. McGue (2020). Health endowments, schooling allocation in the family, and longevity: Evidence from US twins. SSRN Working Paper http://dx.doi.org/10.2139/ssrn.3193396.

Schafer, J. (1997). Analysis of Incomplete Multivariate Data. London: Chapman \& Hall.

van den Berg, G., L. Janys, and K. Christensen (2015). The effect of education on mortality. IZA working paper.

van den Berg, G. J. (2001). Duration models: Specification, identification and multiple durations. In J. J. Heckman and E. E. Leamer (Eds.), Handbook of Econometrics, Volume 5 of Handbooks in Economics, pp. 3381-3460. New York: North-Holland.

van Kippersluis, H., O. O'Donnell, and E. van Doorslaer (2011). Long-run returns to education: Does schooling lead to an extended old age? The Journal of Human Resources 46, 695-721.

Viscusi, W. K. (2013, October). Estimating the value of a statistical life using census of fatal occupational injuries (CFOI) data. Monthly Labor Review, 1-17.

Wehbya, G. and C. Courtemanche (2012). The heterogeneity of the cigarette price effect on body mass index. Journal of Health Economics 31, 719-729. 
Wood, R. G., B. Goesling, and S. Avellar (2007). The effects of marriage on health: A synthesis of recent research evidence. Technical report, Mathematica Policy Research, Inc. 


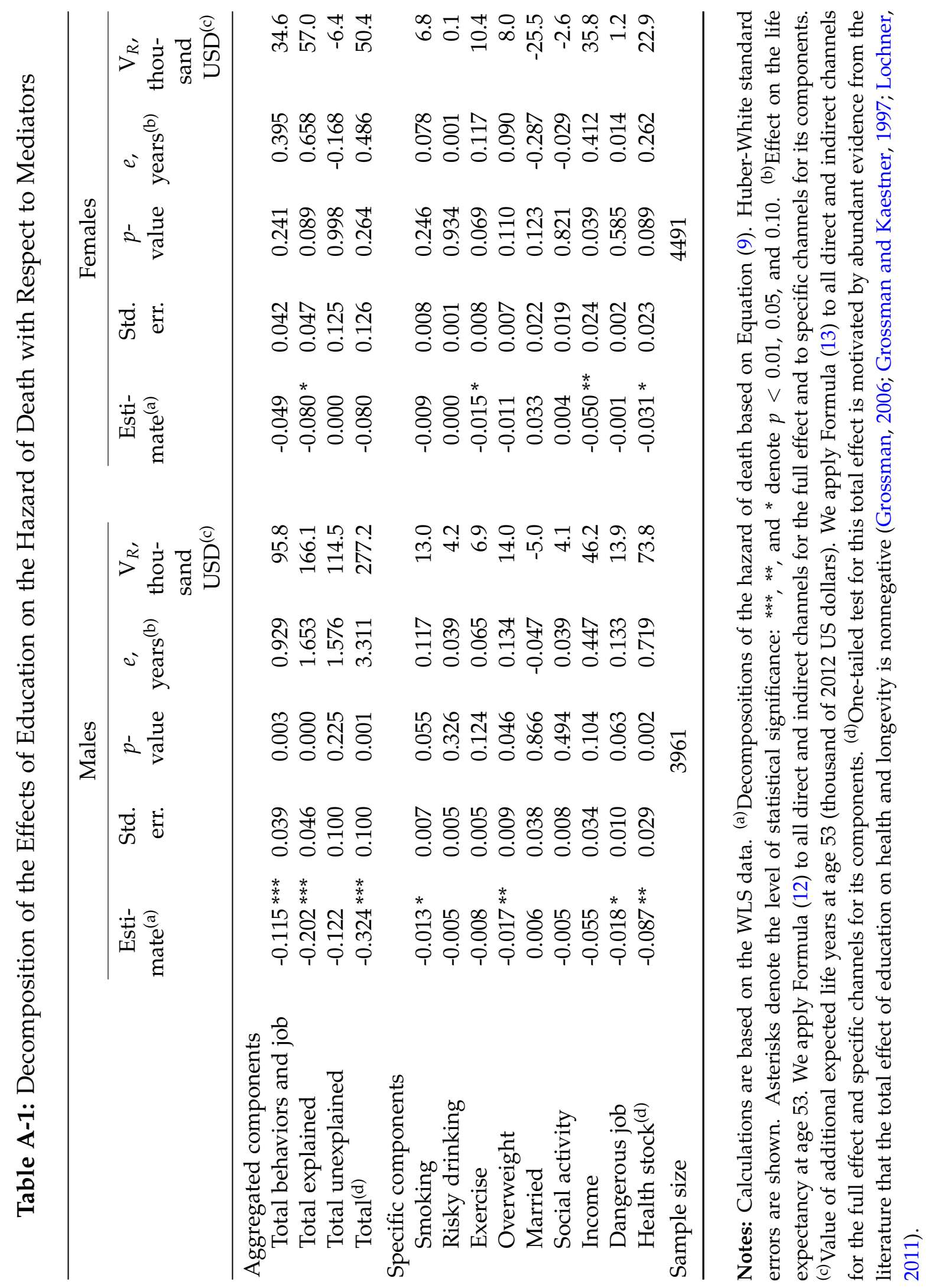

